ISSN : 2682 - 2091

\title{
Criteria of Developing and Improving the New Urban Cities in Northern Egypt Province
}

\section{(The Case of New Minia City)}

\author{
Prof. Dr. Eng. Mohamed Nabawi Abdu Gad Allah- Assistant Prof. Architecture Dept., Faculty of Engineering, \\ University of Minia \\ (Nabawi201333@yahoo.com)
}

Dr. Eng. Amany Nagi Abdel Hafiz- Assistant Lecturer-Architecture Dept., Faculty of Engineering, University of Minia (amanynagihareedy@yahoo.com)

Eng. Sara Tharwat Ahmed Mohamed- Engineering Aid of The Head of Development of New Mallawi City Authority-New Urban Communities Authority- Ministry of Housing, Utilities and Urban Community

(themsai_themsai@yahoo.com)

\begin{abstract}
:-
Statistics and researches ensure that most of the New Cities in Egypt haven't achieved the target they have been established for. They haven't succeeded to attract the population increase in the mother cities. A strange contradiction has appeared between the housing and peopling case in a big number of these new cities where you can see uninhabited building. This case clearly indicates that there is a drawback (defect) that hinders these cities fulfilling the aimed goals.

Consequently, this research aims to shed light on the criteria of improving and developing the urban housing areas in the new cities, applying the study case on New Minia as a model of the New Egyptian Cities, trying to point out how far it has succeeded or failed to realize these criteria and achieve the targeted development.

This study has hypothesized that the lack to apply a comprehensive collection of criteria of improvement and development for housing areas in the New Egyptian cities is the main factor that forbids these cities from reaching the rate of development aimed at.

To prove its hypotheses, the research has applied the following procedure. First; a theoretical study for the aims and criteria of the urban improvement and development planned (set) to develop The New Cities. Second; studying analyzing the applied study in the housing areas in the New urban communities (in New Minia. The research [study] has resulted in a collection of results and recommendations that necessitates setting up a number of criteria for the needed development so as to include in the overall planning for the new cities in order to ensure the comprehensive development and having a secial vision according to the circumstances of each new city.
\end{abstract}

Keywords: Developing and improving the housing areas, The new urban communities, New Minia City. 
Vol. 41, No.2. July 2022

\section{معايير تنمية وتظوير المناطق السكنية بالمدن العمرانية الجديدة بإقليم شمال الصعيد بمصر

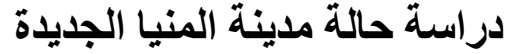

أ.د.م. محمد نبوى عبده جاد الله ـ أستاذ مساعد بقسم العمارة ـ كلية الهندسة ـ جامعة المنيا

(Nabawi201333@yahoo.com)

د.م. أماني ناجي عبد الحافظ - مدرس بقسم العمارة - كلية الهناسة - جامعة المنيا

(amanynagihareedy@yahoo.com)

م. ساره ثروت أحمد محمد- معاون هندسي لرئيس جهاز تنمية مدينة ملوي الجديدة - هيئة المجتمعات العمرانية الجديدة - وزارة الإسكان والمرافق والمجتمعات العمرانية

(themsai_themsai@yahoo.com)

ملخص البحث :

تؤكد الإحصاءات والأبحاث أن معظم المدن الجديدة في مصر لم تحقق المستهدف منها من حيث اجتذاب الزيادة السكانية من الددن

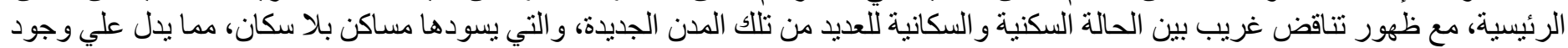
قصور في تحقيق تلك المدن للمستهدف منها.

و عليه، يهدف البحث إلي إلقاء الضوء علي معايير التنمية و التطوير العمر اني للمناطق السكنية بالمدن الجديدة مع التطبيق علي مدينة المنيا الجديدة كمثال للمدن المصرية الجديدة و التعرف علي مدي نجاحها أو فثنلها في تحقيق تلك المعايير ومن ثم في تحقيق نمو ها المستهدف.

وقد افترض البحث أن القصور في تطبيق مجمو عة متكاملة من معايير التتمية والتطوير العمر اني للمناطق السكنية بالمدن المصرية الجديدة هو العامل الاساسي لعدم وصول معدل نمو هذه المناطق للمستهدف منها.

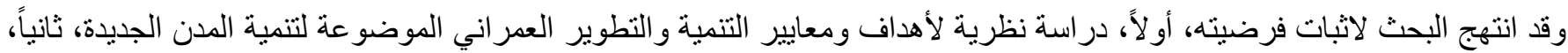

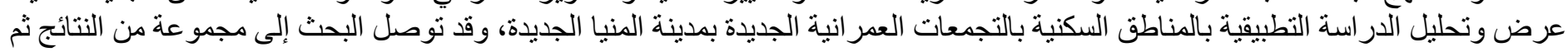

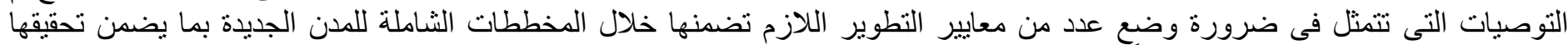
النطوير الثامل ووضع رؤية خاصة تبعاً لظروف كل مدينة من المدن الجديدة القائمة.

الكلمات المفتاحية : تنمبة وتطوبر المناطق السكنية، المجتمعات العدرانبة الجديبة، مدينة الدنيا الجديلة. 


\section{Vol. 41, No.2. July 2022}

العاصمة، مدينة ناصر (غرب أسيوط)، غرب قنا، مدينة ملوي

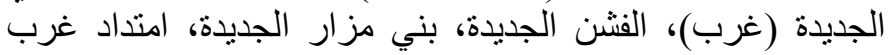

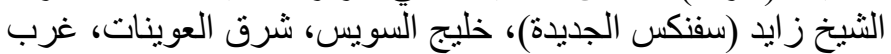
بورسعيد، بئر العبد، أرض كارفور، رشئ رشيد الجديدة، الاسكندرية

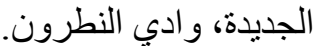

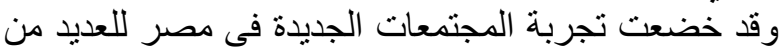

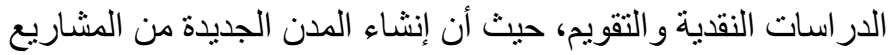

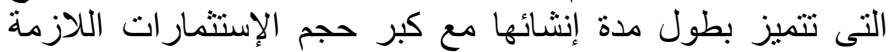

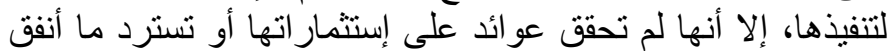

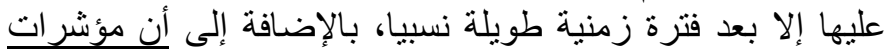

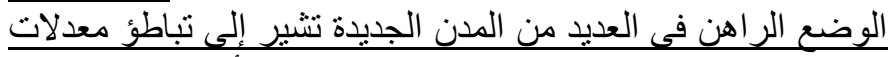

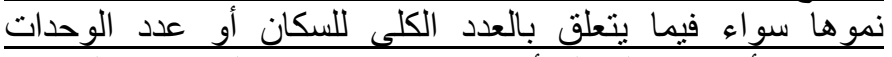

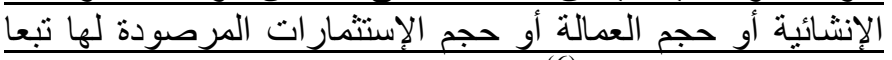
للسياسة القومية الشاملة.

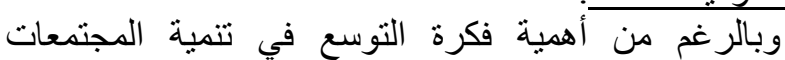

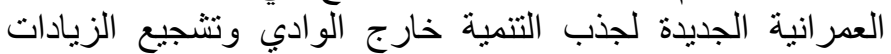

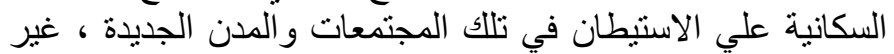

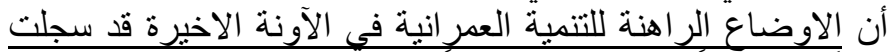

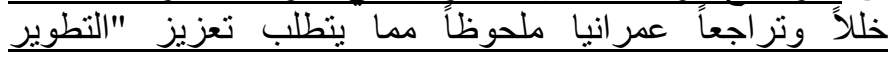

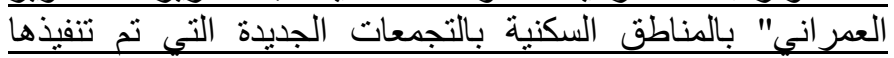

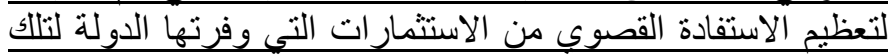
التجمعات.

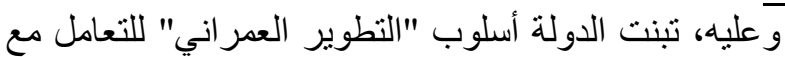

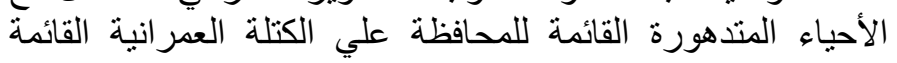

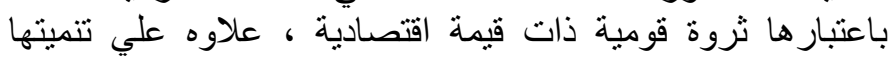

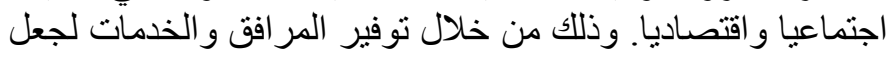

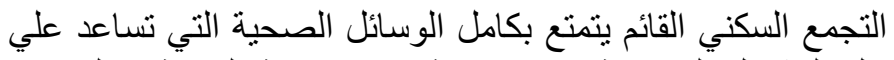

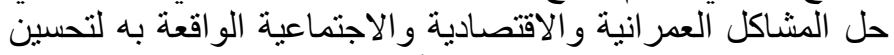

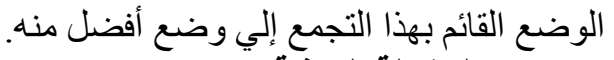
ب- المشكلة البحثية.

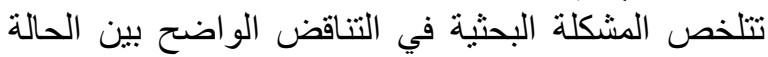

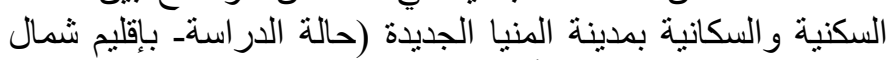

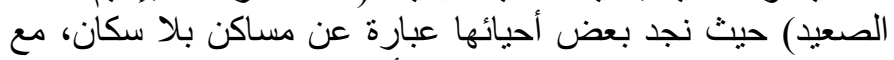
وجود تكدس بشري وسكني بالمدينة الأم.

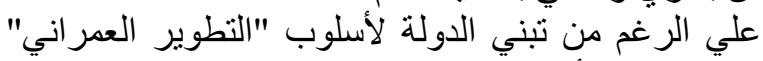

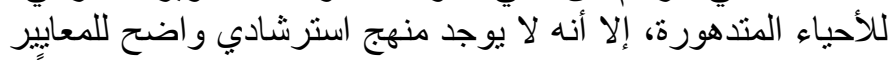

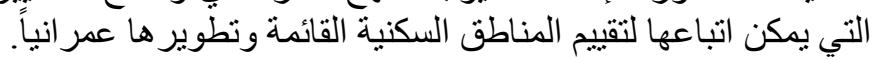

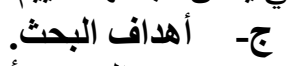

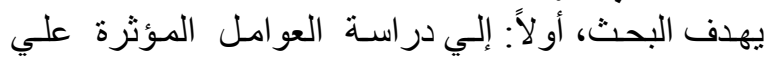

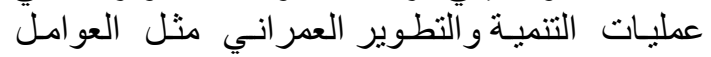

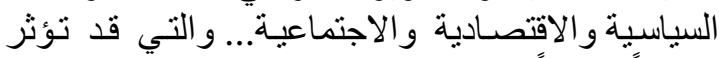

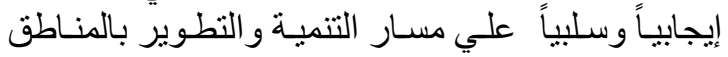
السكنية.

ثانياً: إستخلاص معايير و اضحة لتقييم المناطق السكنية ومن ثم تطوير ها عمر انياً.

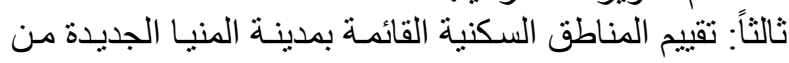

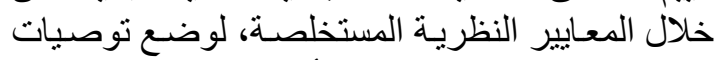

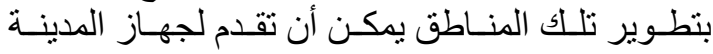

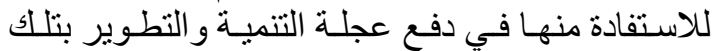
المناطق. لأسطت

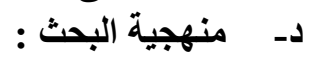
اعتمد البحث على المنهجية التالية :
أ- - مقدمة.

يعتبر إنشاء المدن الجديدة من مشروعات التنمية الكبرى، فمع

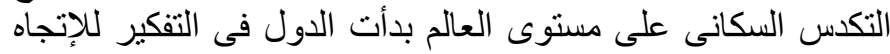

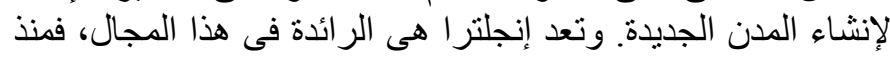

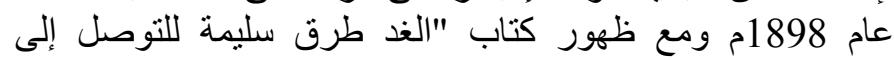

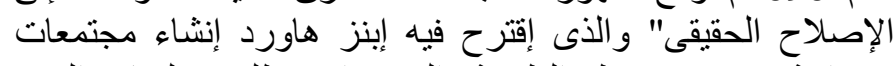

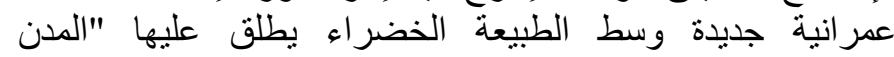
الحدائقية"، وقد بدأت الحكومة البريطانية بعد ذلك حملة لإنشاء

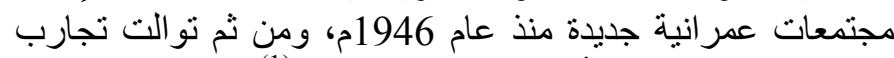
إنشاء المدن الجديدة فى أنحاء متفرقة من مند العالم.

وتختلف دوافع إنشاء المدن الجديدة بالإضافة إلى أنواعها

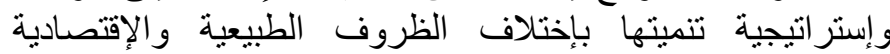

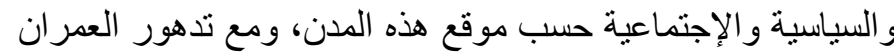

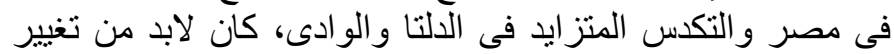

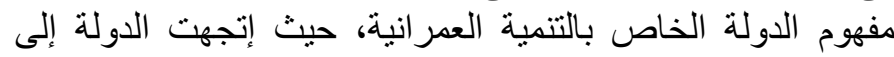

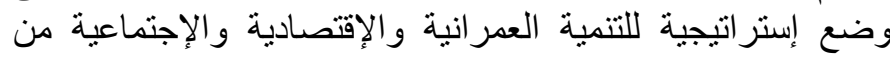
خلال مجمو عة من الخطط الطموحة تهدف إلى رفع الحيز الحئه العمرانى

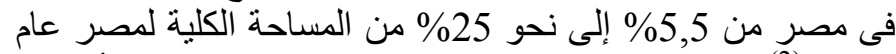

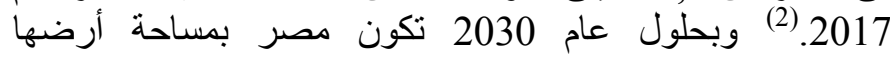
وحضارتها وخصوصية موقعها قادرة على استيعاب سكانها

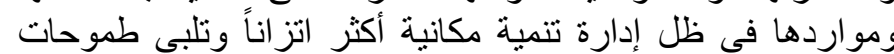

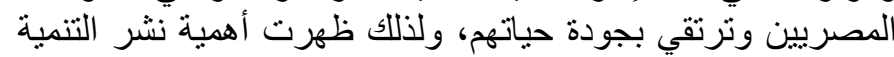

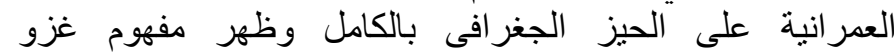
الصحر اء، حيث قامت الدولة بإنشاء العديد من التجمعات العمر انية

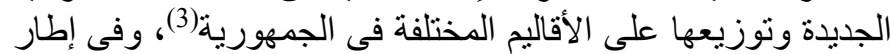

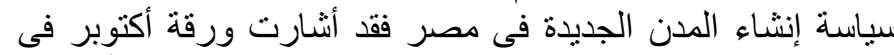

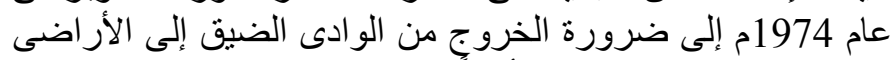

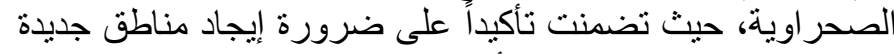

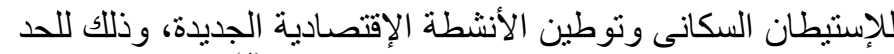

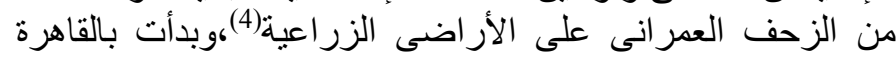

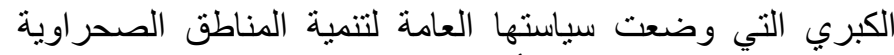

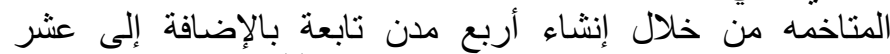

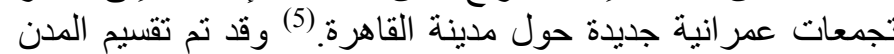

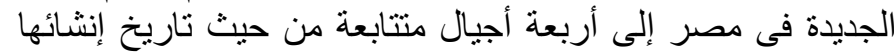

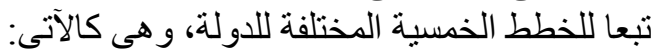

الجيل الأول: ويبدأ من منتصف السبعينات من القرن العثرين

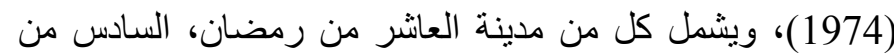

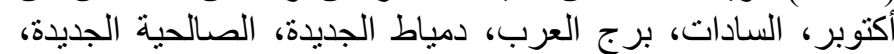
15 مايو، السلام. المباد. الجيل الثانى: بدأت في أوائل الثمانينيات من القرن العثرين

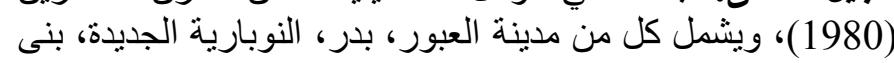
سويف الجديدة، المنيا الجديدة. الجيل الثالث: بدأت في منتصف الثمانينات من القرن العثرين

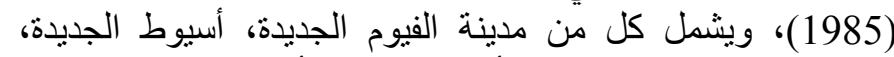
سوهاج الجديدة، قنا الجديدة، الأقصر الجديدة، أسوان أسوان الجديدة.

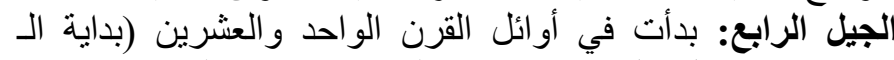

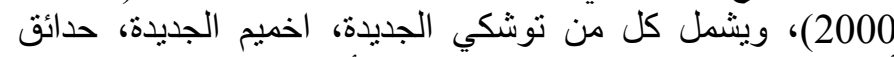

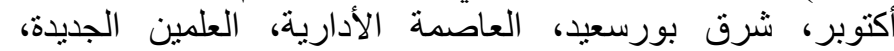
المنصورة الجديدة، مدينة الجلالة، الإسماعلية الجديدة، حدائق الأقداء

Received:9 December, 2020, Accepted:24 February, 2021 


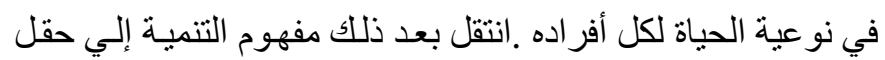
السياسة منذ ستينيات القرن العشرين حيث ظهر أثر كحقل منفرد يهتم

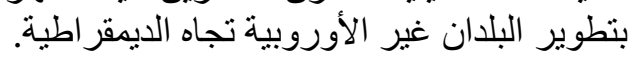

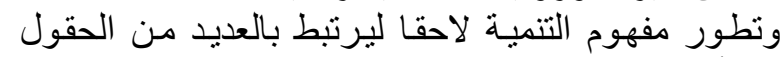

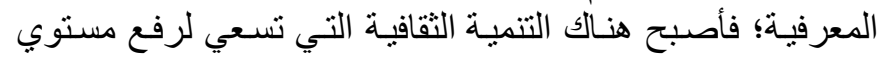

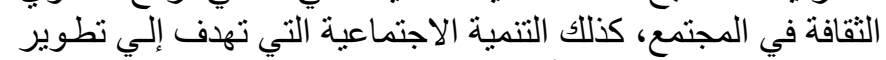

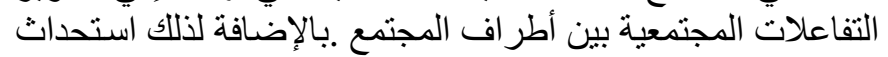

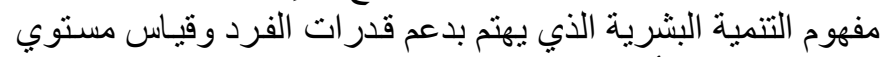
معيشته وتحسين أوضاعه في المجتي المتهع (8).

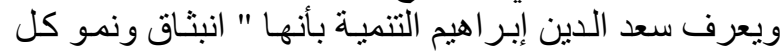

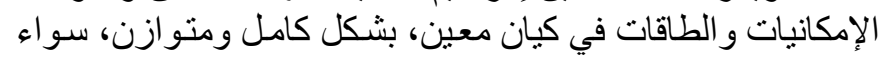

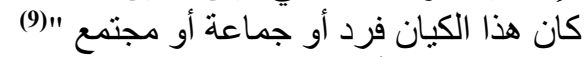

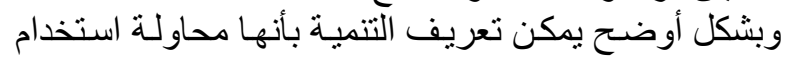

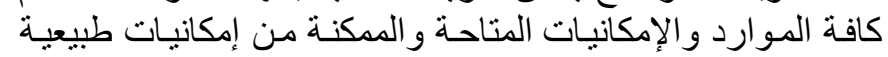

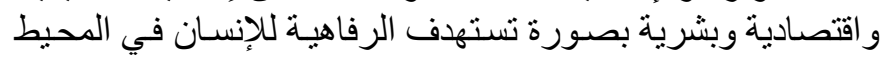

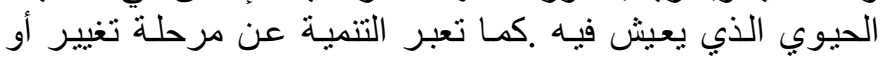
إصلاح في:

$$
\text { - } \begin{array}{r}
\text { - } \\
\text { - }
\end{array}
$$

-

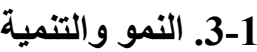

يرتبط مفهوم النمو بالكم، فهو يركز على زئه زيادة الحجم (مثل: الناتج

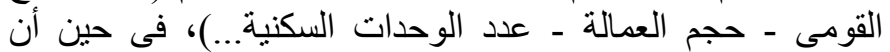
مفهوم التنمية يرتبط بالكيف ويركز على إحداث تغير ات كيفية فى التى

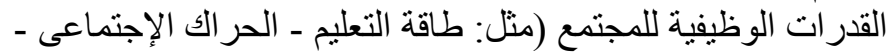

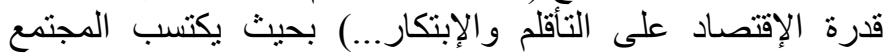

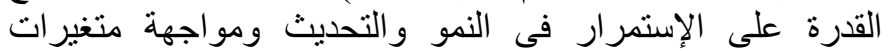
المستقبل(10)

بالإضافة إلى أن المفهوم العام للتنمية هو تحقيق لكيفية النمو بهدف

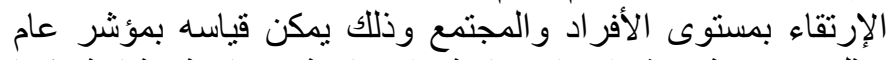

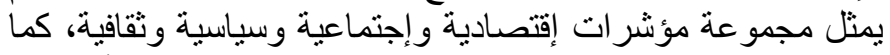

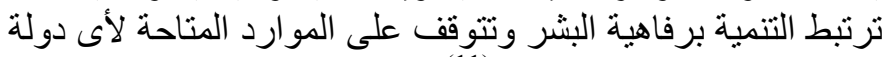

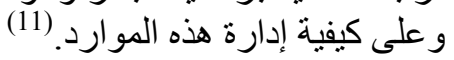
ـ-1

- - وهو مفهوم محدد يطلق فقط على أحد أنماط التجمعات الجديدة،

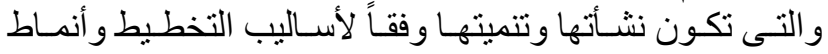
التصميم الحضرى (12)

وهي تللك التى تنشأ لتحقيق أهداف يتم التخطيط لهـا مسبقا وفقا

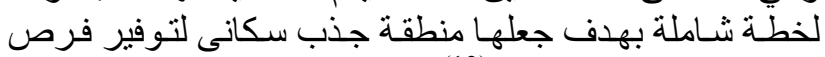

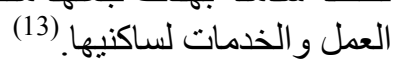

H.U.D كما عرف قسم الإسكان و التنميـة الحضـرية الأمريكية

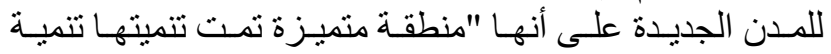

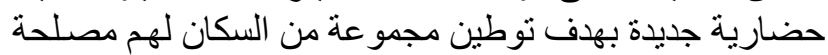

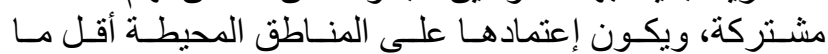

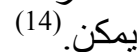

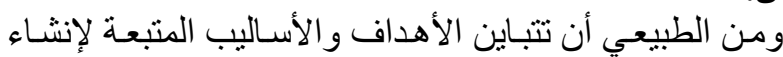

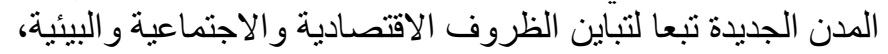

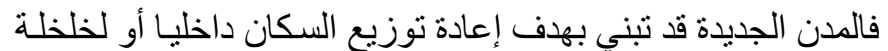

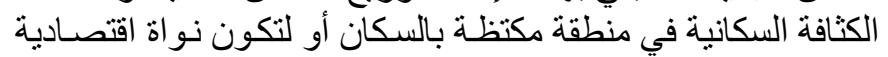

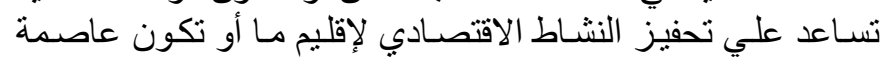

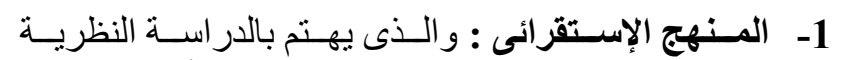

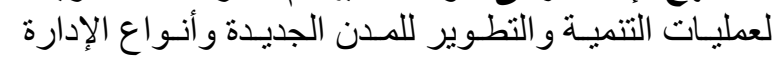
العمر انية ومعايير تطوير المناطق السكنية.

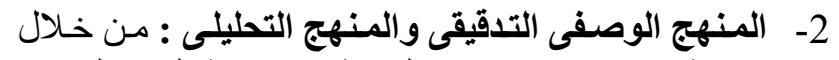

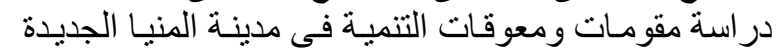
عن طريق:

- الوصول إلي أخر المستجدات بالمدينة وتطور المخططات الخاصة بها و آخر الاسعار وخطة التنفيذ

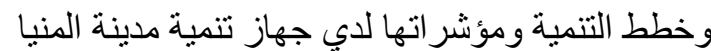
الجديدة زيارات ميدانية لمناطق سكنية تحتاج إلي تتمية وتطوير بالمدينة.

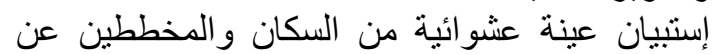
معايير التنمية المطبقة بالمدينة.

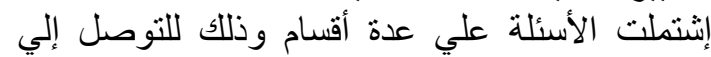

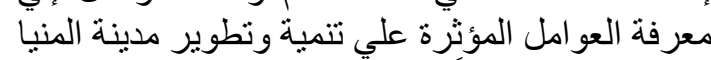

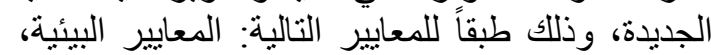

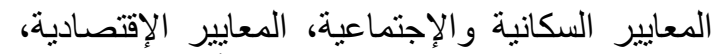

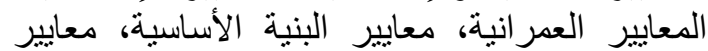
إدارية وسياسية. معظم الأسئلة وضعت في صورة إختياسية إنبار ات لجعل إجابات السكان محددة وكذلك لسهولة تحليلها بأسلوب الإبل الإحصاء الكمي.

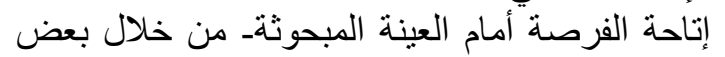

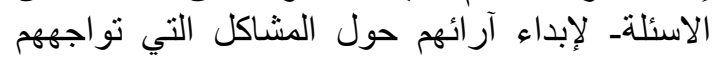

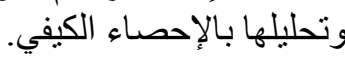

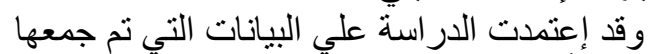

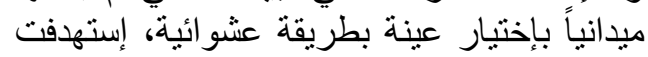
5\% من عدد الأسر من كل حي من أحياء المدينة

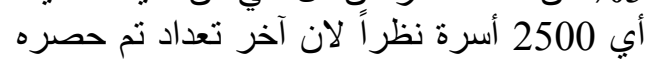

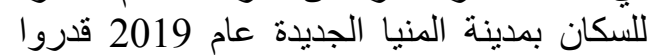
بحوالي 50000 نسمة من خلال جهاز مدينة

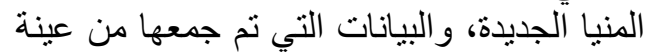

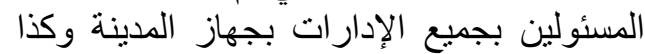

$$
\text { نو اب رئيس الجهاز . }
$$

ثث تثم استخلاص المشاكل وتحليلهاز ورضع توصيات لحل تللك المشكلات.

1- الإطار النظرى لتنمية المدن الجديدة

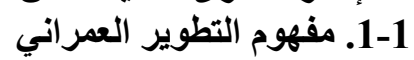

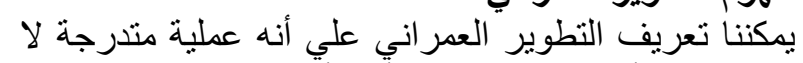

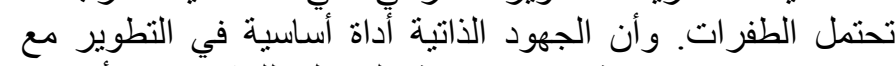

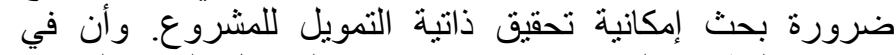

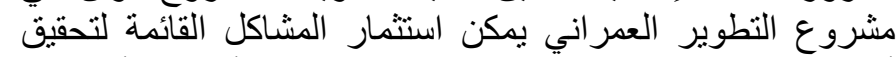

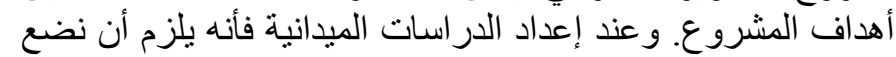

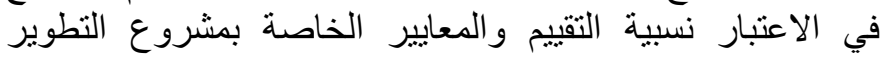

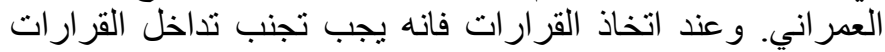

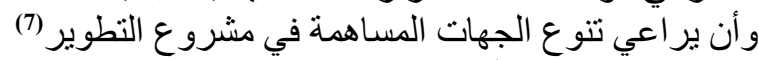
2-1 وان براعي تلوع التجمية

برز مفهوم التنمية بصورة أساسية منذ الحرب العالماتية الثانية

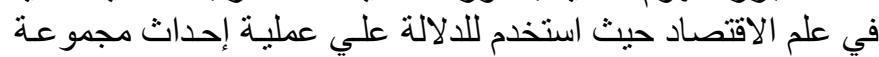

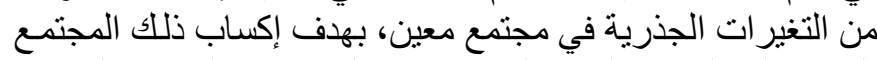

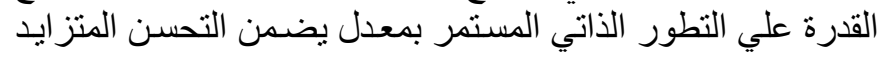


• وجود آليات للتحكم فى العمران والإمتدادات العمرانية

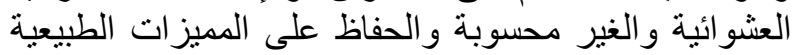
و البيئية للمجتمع الجديد.

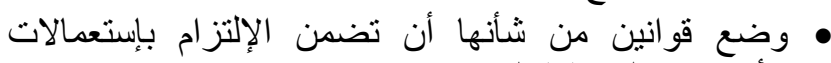
الأر اضى بالمخطط العام. • تحسين الظروف المعيشية للسكان لتلافى حدوث هجرة غير

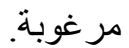
• • در اسة القاعدة الإقتصادية التى تقوم عليها المدن الجديدة.

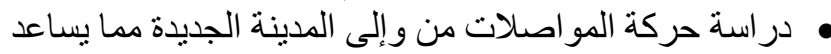
على إقبال السكان على الإقامة بهان • وضع خطط لتطوير المجتمع من حيثل الإنهان الإسكان والبنية

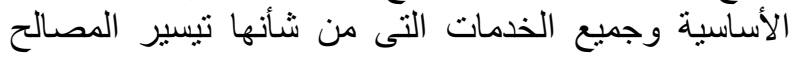

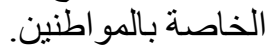
• وضع سياسة تضمن مستوى معيشى متميز للسكان.

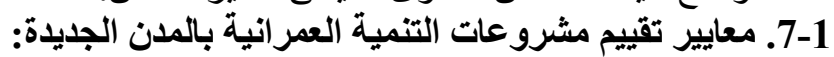

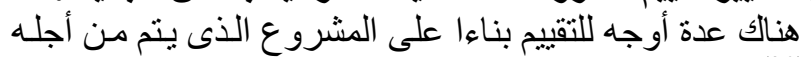

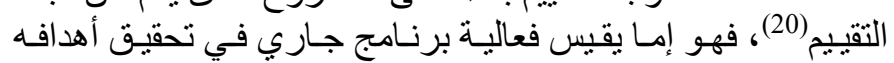

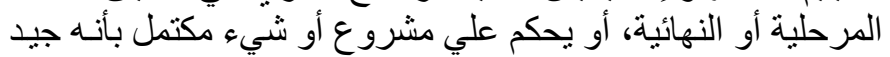

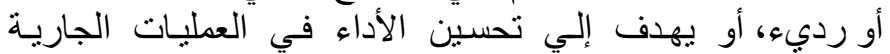
وتتضمن معايير تقييم "مشروعات التنمية العمرانية" بوجه

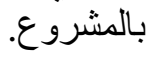

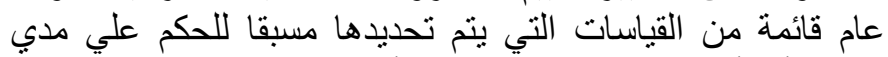

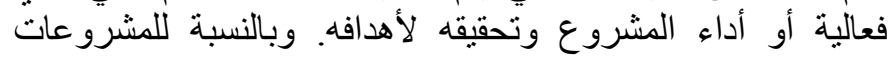

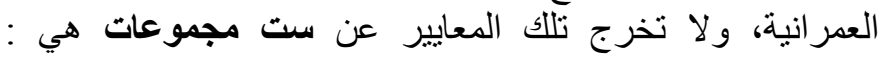

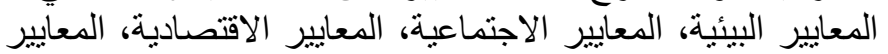

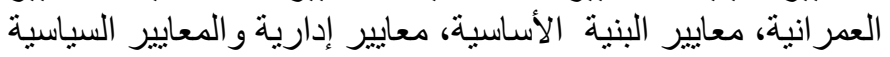

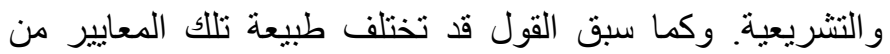

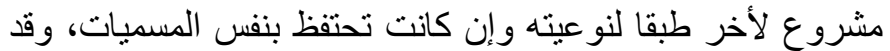

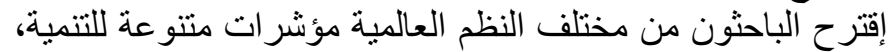

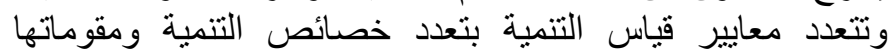

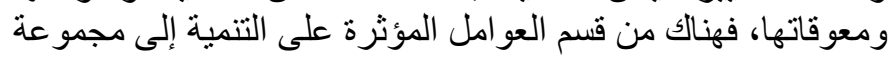

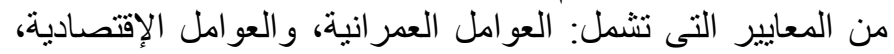

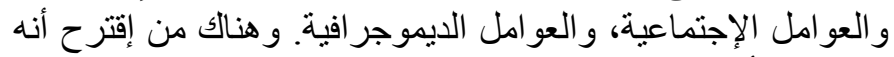

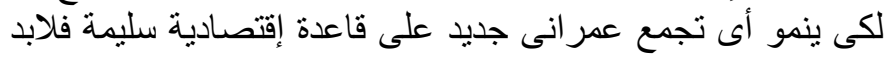

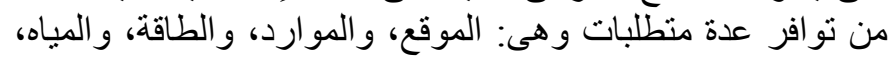

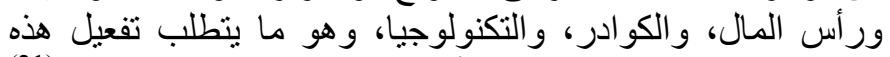

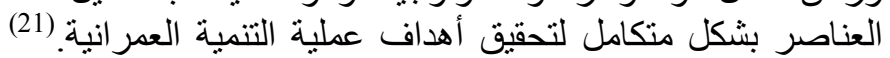

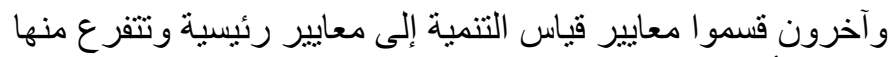
عناصر أخرى فر عية.

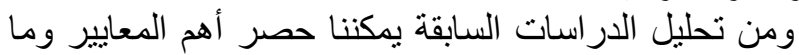

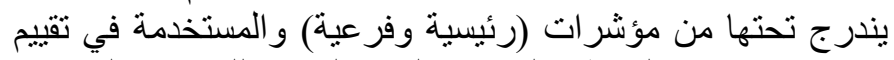

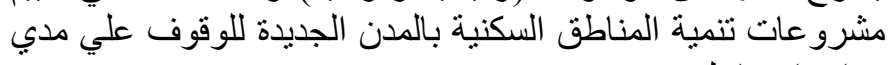
نجاحها فيما يلي: تلئية

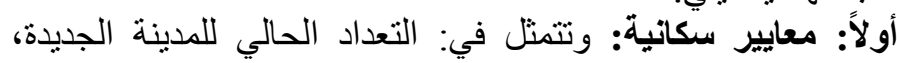

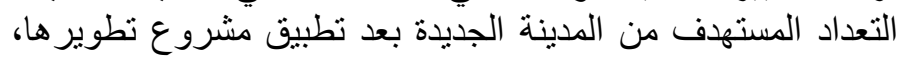
مدي نجاح مشروع التطوير في تحقيق التعداد المستهدف في سنة سنة نطئ

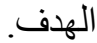
ثانياً: معايير اقتصادية: يتم قياس المعيار الإقتصادي للوقوف علي

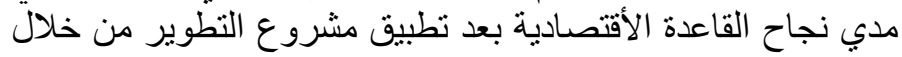

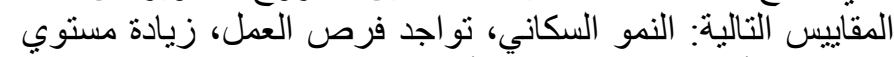
الدخول و الأجور، ومن ثم مدي تأثثيره علي معدل جذب النب السكان.

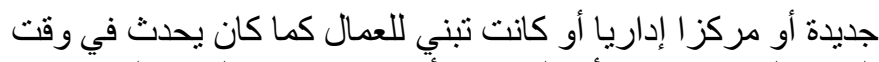

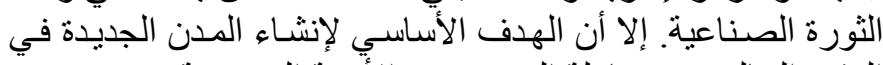

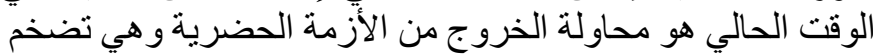

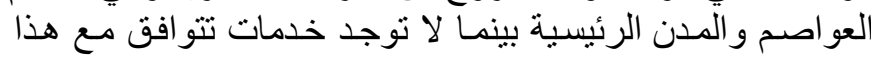

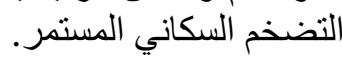

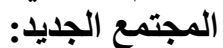

تم تعريفه بأنه مخطط جديد لتنميـة منطقة كبيرة الحجم ويكون

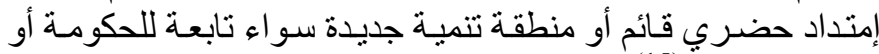

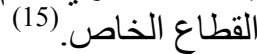

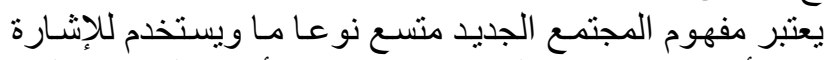

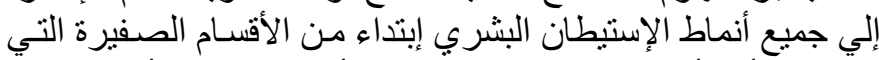

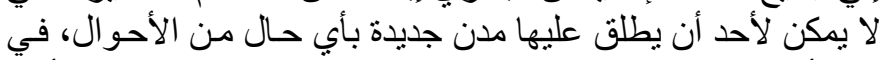

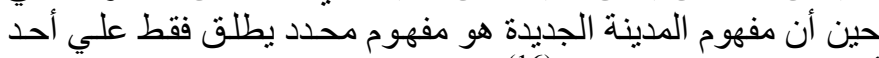
أنماط المجتمعات الجديدة. (16)

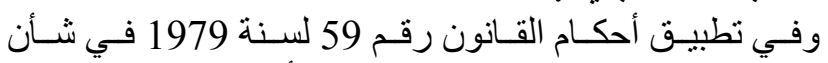

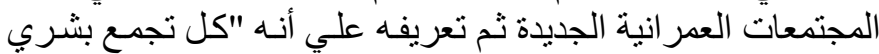

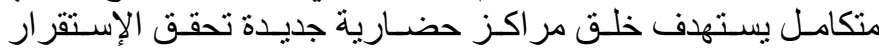

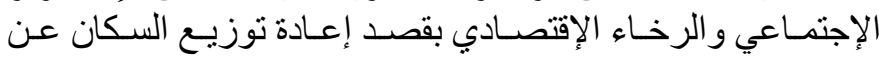

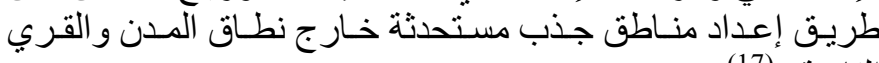

القائمة" (17) إعداد من

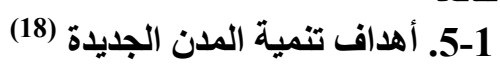

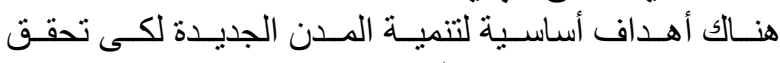

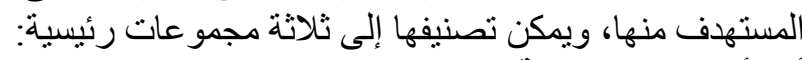

أـ الأهداف الاجتماعية منافي

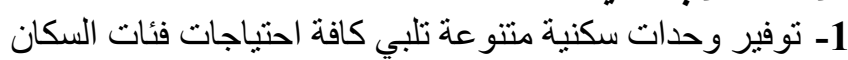

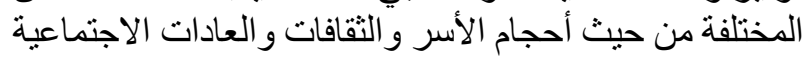
الخاصة بهم.

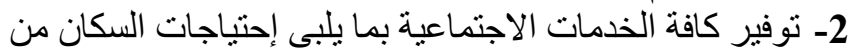

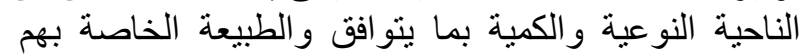
اجتماعياو اقتصاديا.

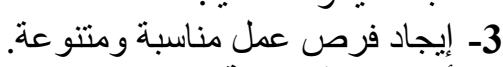
ب- الأهداف الإقتصادية 1- خلق قواعد اقتصادية جديدة تهدف إلي تحقيق توازن الإني اقتصادي علي مستوى الإطار الأشمل الإقليمي و القوني توني.

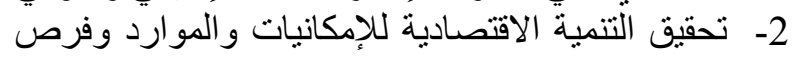

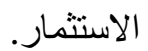

3- تشجيع الاستثمار واجتذاب رؤوس الأموال الخارجية. ج- الأهداف العمرانية 1- إعادة تشكيل نمط العمرانية العئ علي المستوي القومي بما يتو افق مع استر اتيجية التنمية المستندامة.

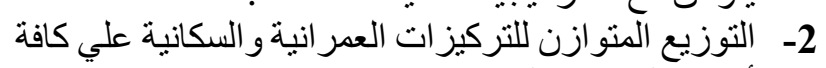
أرجاء الخريطة القومية.

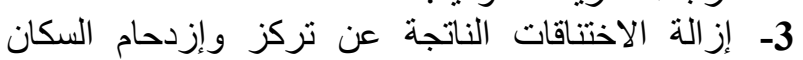

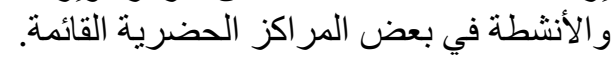
4- الانتشار الاستراتيجي لتحقيق السيادة القومية علية كامل

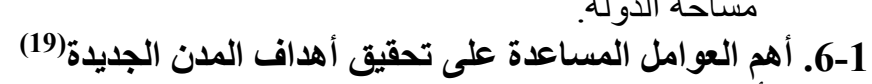

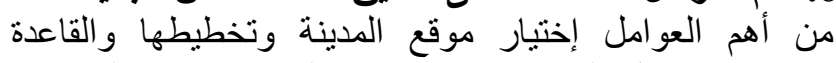
الإقتصادية ومر احل التنفيذ وما بعد تنفيذ المدينة، وفيما يلى سرد

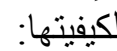

• وجود استر اتيجيات ثابتة لإدارة الأرض و تنظيم ملكيتها. 
Vol. 41, No.2. July 2022

وفي عام 2000 تم تعديل ومراجعة المخطط العام للمدينة لعدة

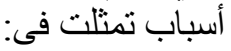

مرور طريق (القاهرة ـ المنيا الصحر اوى الثرقي) قاطعاً

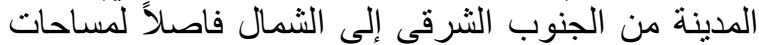
إستعمالات كبيرة من المخطط العام.

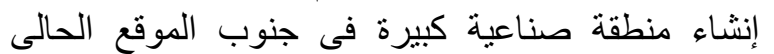

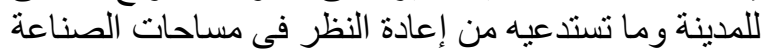
المقترحة بالتخطيط العام للمدينة.

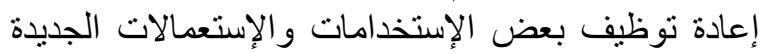
بالمدينة و التى لم يستو عبها المخطط السابق من أراضى الإنى

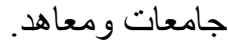

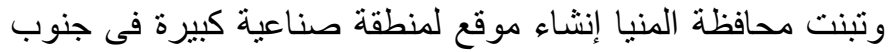

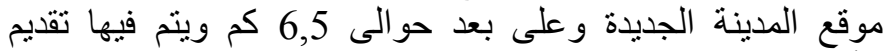

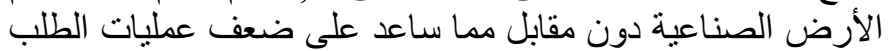
على المناطق الصناعية بالمدينة الجديدة، وكان قاعل قد نم تنفيذ منطقة صناعية واحدة بالفعل ولذلك فقد إستدعى المخطط العام العام للمدينة إلغاء

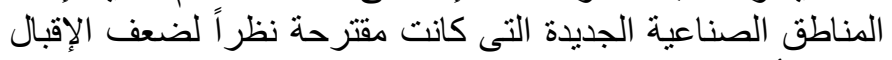

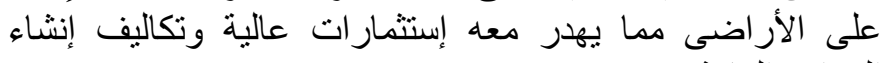

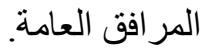
وقد تم إعادة تخطيط المدينة على أن تشمل ثمانية أحياء سكنية

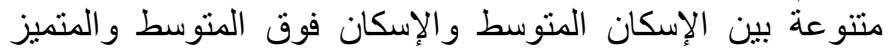

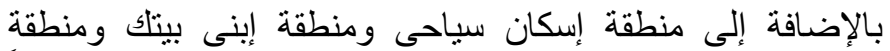
الصناعات الصغيرة و المنطقة الصناعية، وقد بلغ الصناف تعداد السكان طبقاً

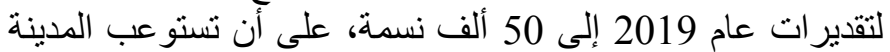

تعداد 648 ألف نسمة سنة 2050 طبقا للار اسة العمر انية للمدينة (24).

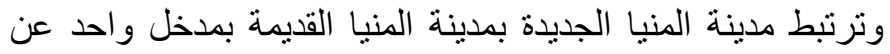

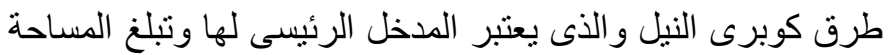

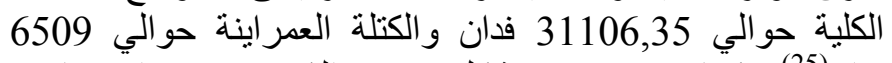

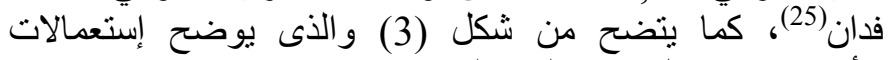

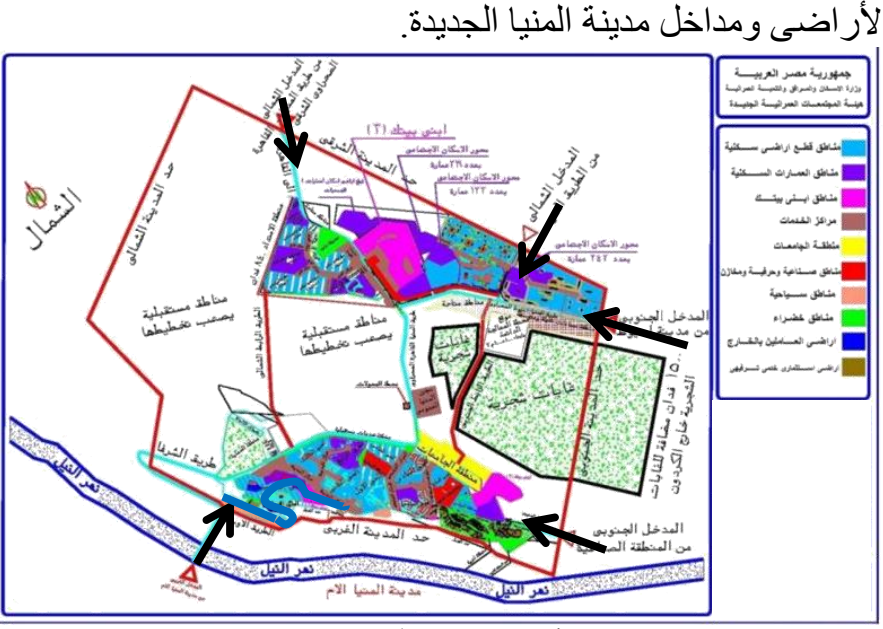

شكل (3): إستعمالات الأراضى بمدينة المنيا الجديدة ومداخلها. (26)

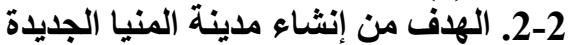

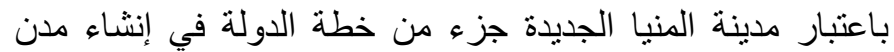
جديدة، فيعد الهدف من إنشائها:

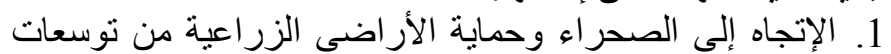

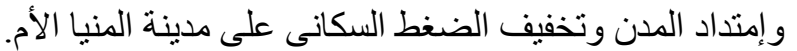

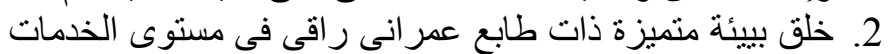

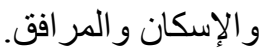

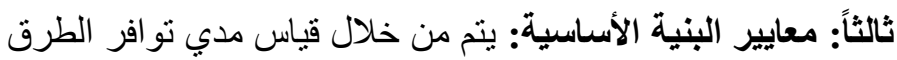

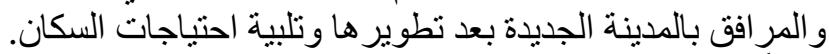

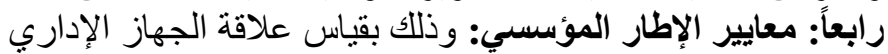

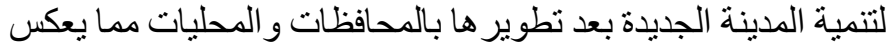

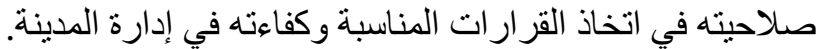

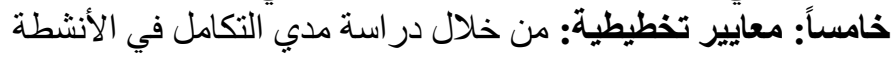

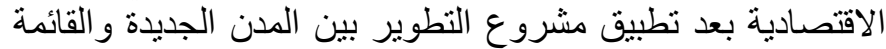

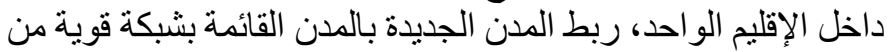
المو اصلات، النقل و المو اصلات الصات داخل المدن الجدائل الجديدة.

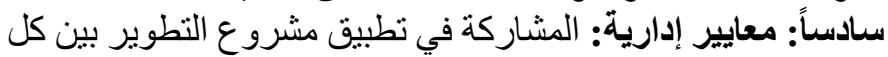

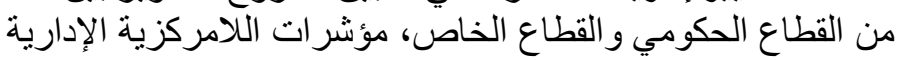

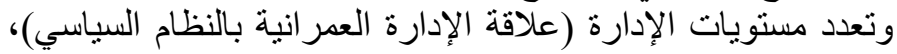

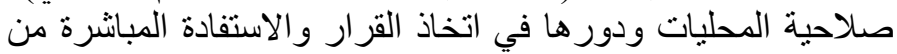

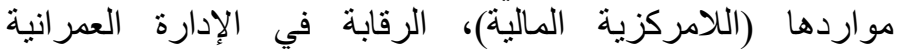
ومستوياتها. سابعاً: معايير خدمية: تحقيق الاستفادة القصوي من المرافق و الخدمات و المقومات الاقتصادية المناحة وتطوير ها لتحقيق التطوير

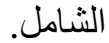
ثامناً: الحوافز: من خلال معرفة ودراسة التسهيلات التي بمكن

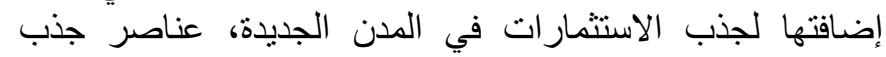

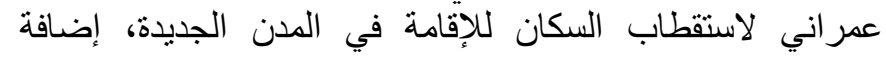
مجموعة من اللوائح والتشريعات للمساهمة في زيادة عملية تطوير لإني

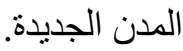

2- التعريف بمنطقة الدراسة (مدينة المنيا الجديدة).

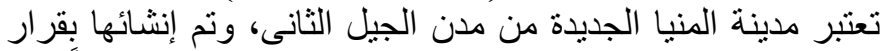
مجلس الوزراء رقم 278 لعام 1986 وبدأ العمل بهان ونها فعلياً عام الجيان

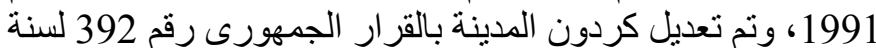

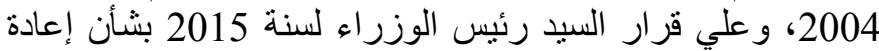

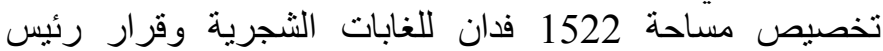

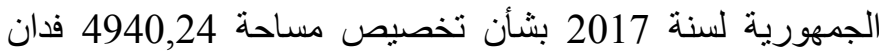

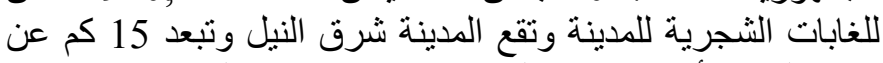

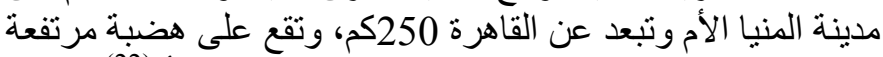
بحو الى 137 متر فوق سطح البحر شرق مدينة المنيا الأم (22.

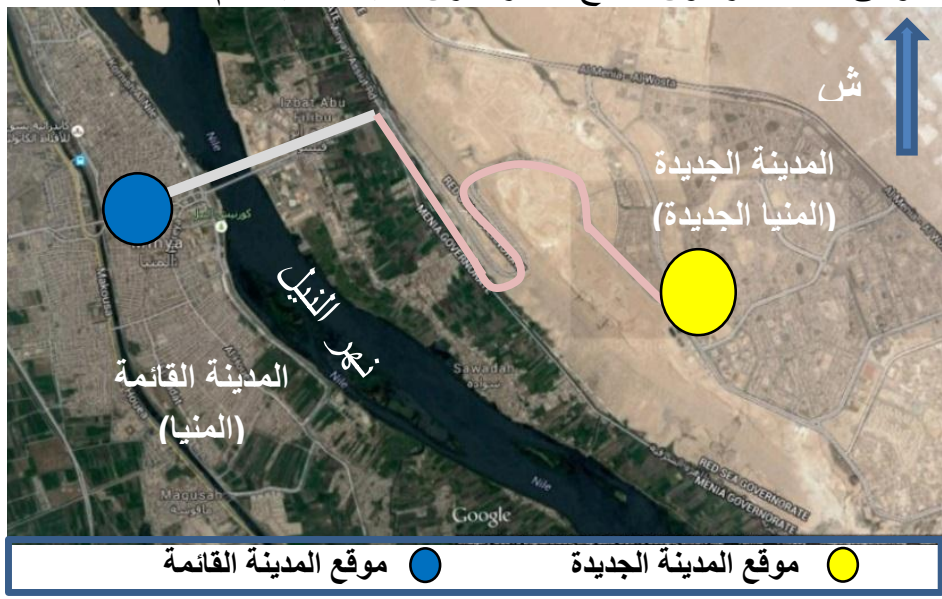

شكل (2): خريطة توضح موقع المنيا الجديدة بالنسبة للمدينة الأم. (23)

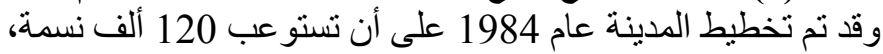
ونم تخطيطها على أن تسنو عب أربعة أحياء سكنية تطل على تلى مركز

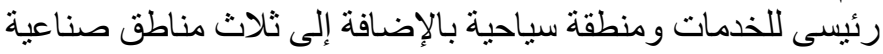

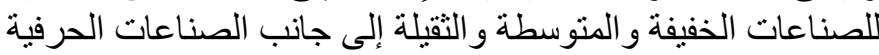
التى تتوزع على أحياء المدينة. 


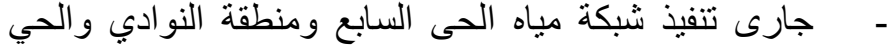

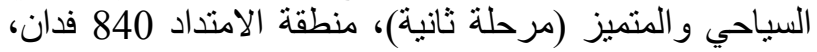

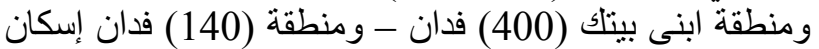
اجتماعي ( مرحلة أولى). جارى تنفيذ شبكات المياه الخاصة بمنطقة 1400 فدان

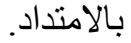
جارى طرح خط تغذية رئيسي بقطر 1200 مم .

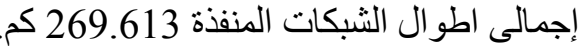

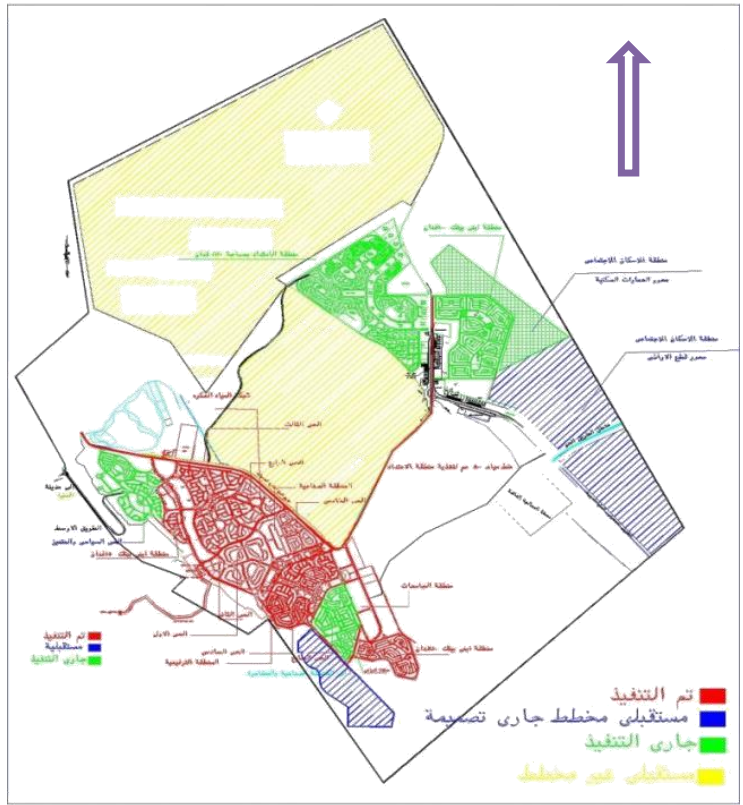

شكل (5): موقف شبكات ومحطات المياه

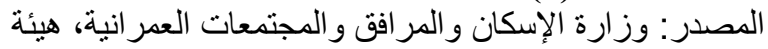

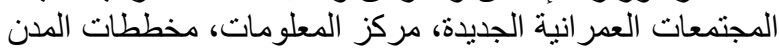

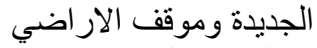

ونجد أن كفاءة محطة المياه بالمدينة ضعيفة ولا لا تعمل بالكفاءة

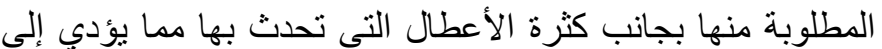

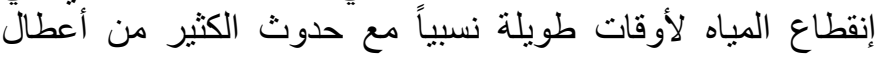

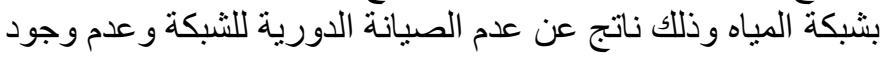

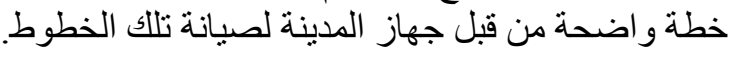
ثانيا: الصرف الصحس.

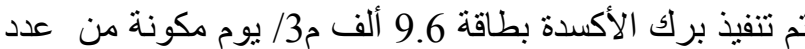
(5) أحو اض ترسيب و أكسده.

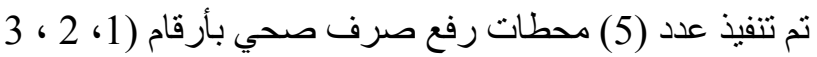
، 4 ، محطة ابنى بيتلك 2). تم تنفيذ محطة التخلص من مياه برك الأكسدة. تم تنفيذ شبكات الصرف للأحياء (الأول و الثاني والثاء والثالث

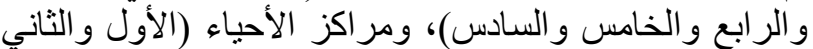

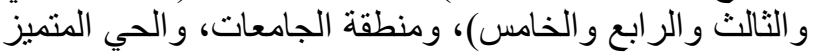

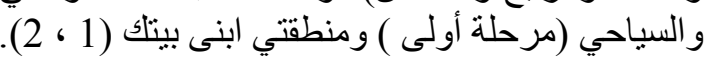
جارى تنفيذ شبكة صرف الحى السابع ومنطقة النو ادي والحي الحي الحئي السياحي والمنميز (مرحلة ثانية)، منطقة الامتداد 840 فيكة فدان،

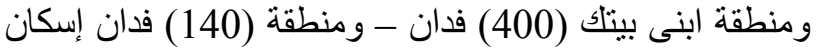

$$
\text { إجتماعى (مرحلة أولى). }
$$
جارى تنفيذ محطتي رفع رقم (5-6) .
3. المساهمة فى حل المشكلة السكانية بمصر عامة وذللك بخلق بكائ

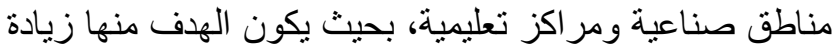

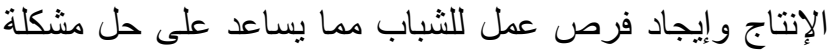
البطالة و العمالة الز ائدة. 4. دعم الأنشطة السياحية ودعم الإقتصاد القومة القيى والإقليمي

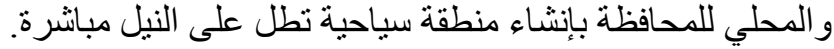

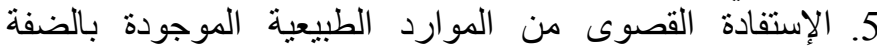

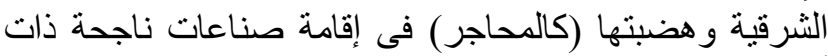
6أساس إقتصادى سليم. 6. الإستفادة من الإستثمار ات المحلية و القومية فى مجالات الصناعة و الزر اعة و السياحة و الإسكان.

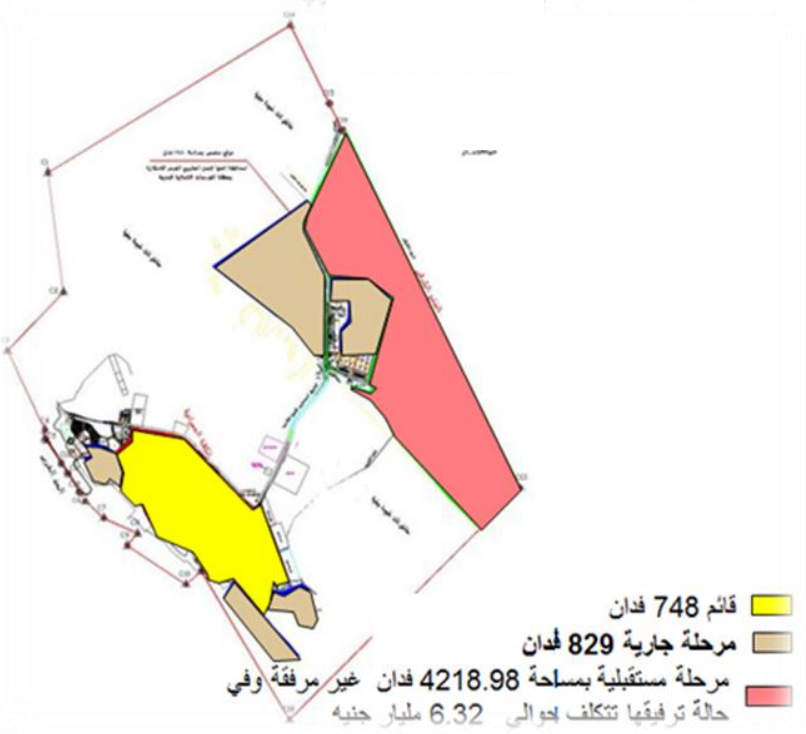

شكل (4): مراحل نمو مدينة المنيا الجديدة.(27)

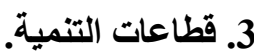

فيما يلي سيتم تحليل قطاعات التتمية بالمدينة وما تم تتفيذها حتي عام 2019م (28). أجاري تنفيذ شبكات المياه 1400 فدان بالامتداد. تم تنفيذ محطة آبار بطاقة 10 آلاف م3/ بوم مكونة من 7 آبار

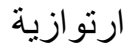
تم تتفيذ محطتي رفع مياه تم تنفيذ محطة تحليه مياه الآبار المؤقتة بطاقة 10 ألاف م3/

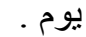

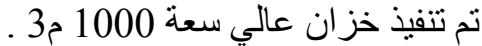
تم تتفيذ المرحلة الأولى من محطة تنقية المياه الدائمة بطاقة 45 تلبة

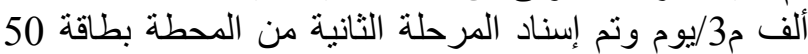

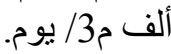

تم تنفيذ خزان علوي سعة 3000 م3.

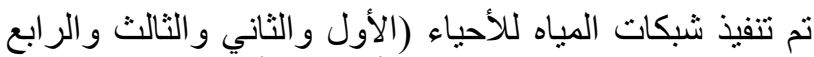

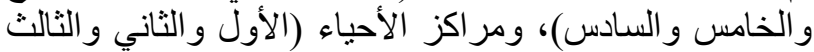

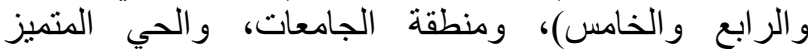
و السياحي (مرحلة أولى ) ومنطقتي ابنى بيتك (1 ، 2). 
Vol. 41, No.2. July 2022

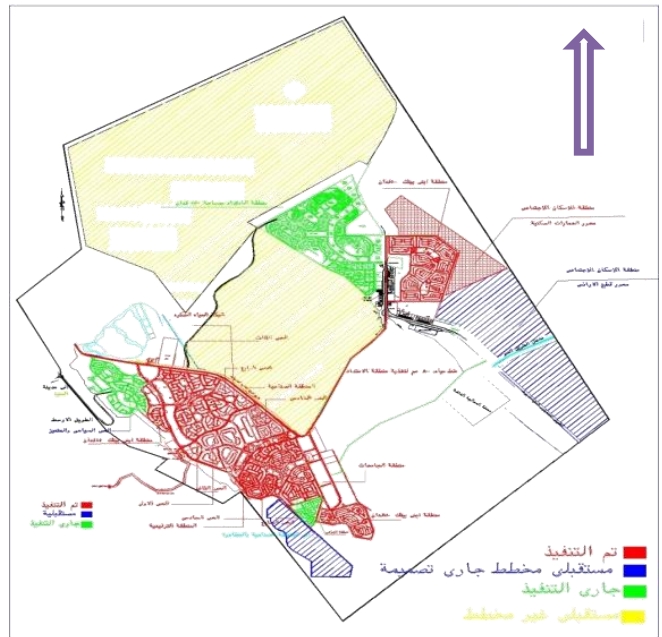

شكل (7): موقف أعمال الكهرباء

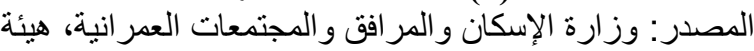

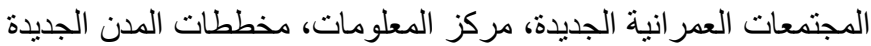

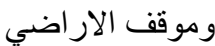

ونجد أنه نظراً لعدم وجود الكثافة المطلوبة والمستهدفة بأحياء

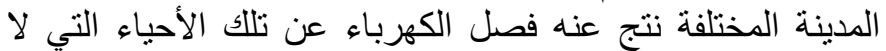

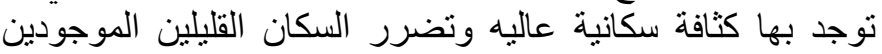

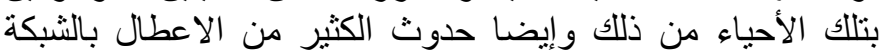
نتيجة لعدم القيام بالصيانة الدورية اللازمة لتلكاء الثيات الثبكات. رابعا: الطاقة المتجددة بالهائ

- تم تنفيذ محطة طاقة شمسية أعلي مبني الجهاز بقدرة (45) وات . تصفئ.

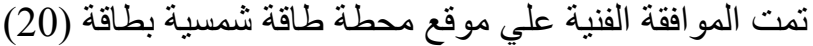

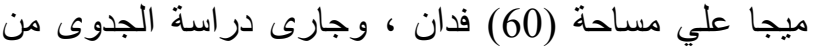
تنفيذ المرحلة الاولي بطاقة 5 ميجا علي مساحة 15 فيدان 15 فدان

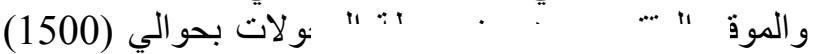

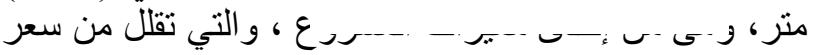
التكلفة

تم المو افقة علي تطبيق منظومة المياه الرمادية بالمدرسة التعليم الأساسي بمنطقة 1360 فدان.

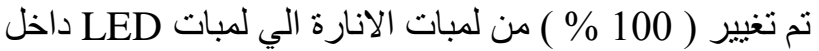
جهاز الددينة ، والذى أدى إلى وافر في الاستهلاك بنسبة التيات . \%30

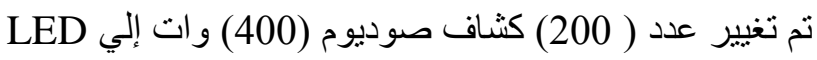

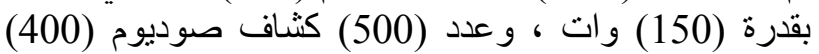

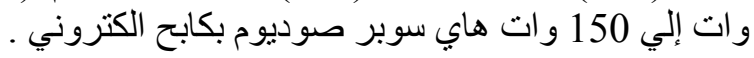
تم إنارة مدخل المدينة من بداية طريق الجيش حتي كمين الصفا

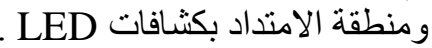

تم استخدام السخانات الثمسية بالمدرسة البريطانية بمنطقة

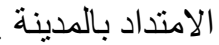
إلا اننا نجد أن مدينة المنيا الجديدة متأخرة نسبياً في إستخدامم الطاقة المتجددة.

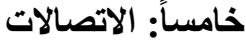 مبنى السنترال}

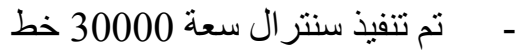
تم تشغيل 3000 خط كمرحلة أولى .
جارى تنفيذ المرحلة الأولى من محطة المعالجة للصرف

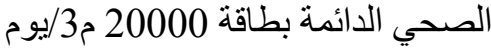
إجمالى اطو ال الثبكات المنفذة 221.044 كم

تم تنفيذ عدد 4 محطة رفع وجاري تنفيذ عدد 2 محطة رفع. جاري تنفيذ شبكات الانحدار للحي المتميز والسياحي (مرحلة ثانية) ومنطقة 140 فدان اسكان اجتماعي.

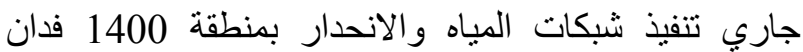

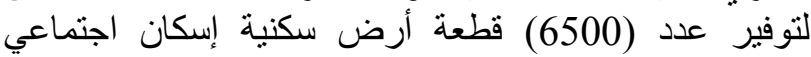

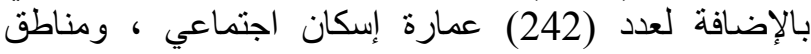
خدمية متنو عة لخدمة المنطقة.

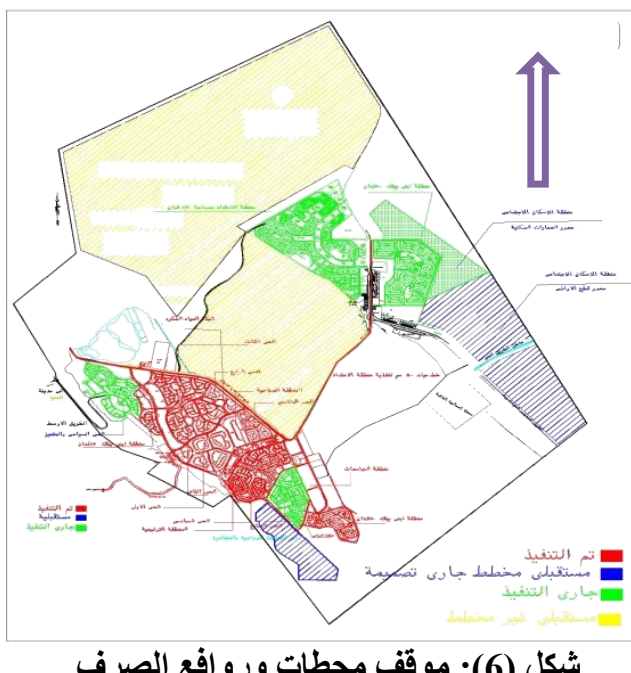

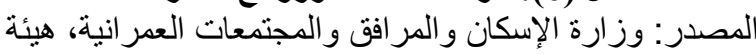

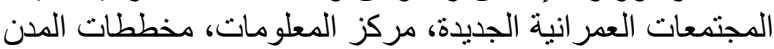

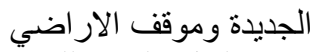

وعدم الإنتهاء من تنفيذ الحل الدائم للصرف الإن بالمدينة أدي إلي

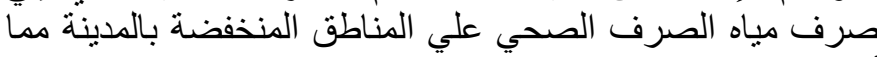

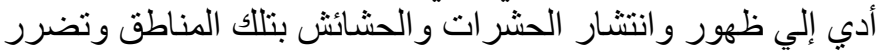

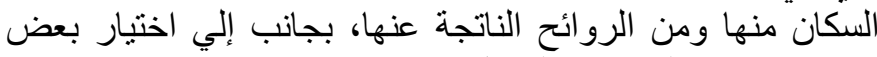

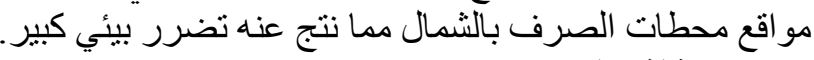
ثنالثا: الكهرباء.

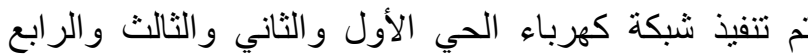

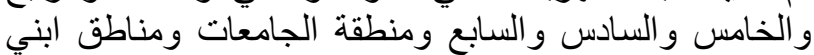

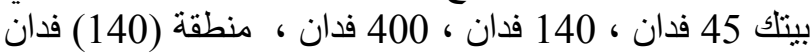

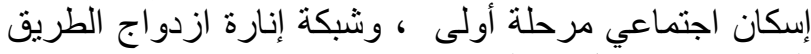

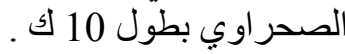
جارى تنفيذ شبكة كهرباء مر اكز الأحياء ومنطقة النوادي

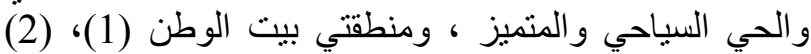
ومنطقة الامتداد ، و الطريق الرابط بين وصئة وصلة طريق الجيش

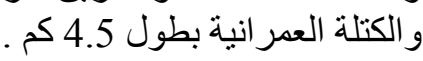
إجمالى اطو ال الثبكات المنفذة 1347.5 كم.

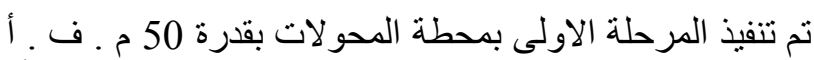
وجارى عمل موزع التوسعة لتصل سعة المحطة 100 م.ف. أ. 
جارى تنفيذ أعمال الطرق للطريق الرابط بين وصلة طريق الجيش و الكتلة العمر انية بطول 4.5 كم .

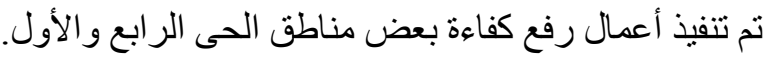
إجمالى اطو ال الطرق المنفذة 194.75 كم.

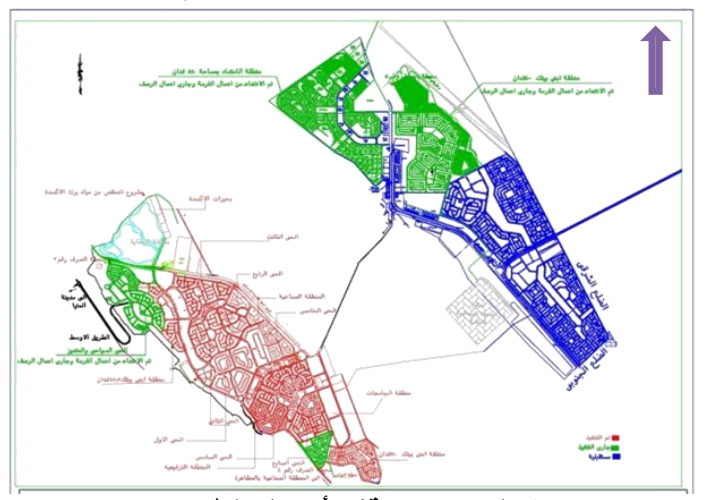

شكل (9): موقف أعمال الطرق

المصدر: وزارة الإسكان و المر افق و المجتمعات المعات العمر انية، هيئة المئة

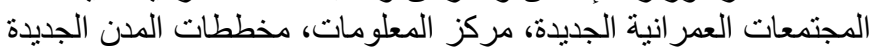

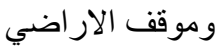
سابعاً: قطاع الغاز:

تم توقيع البروتوكول بين شركة وادي النيل للغاز الطبيعي

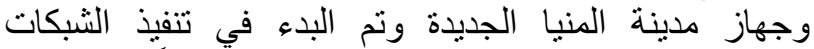
و الخطوط الرئيسية ومحطة تخفيض الضغط تمهيداً لضخ الضغاز الطبيعي للمدينة. ونجد أن عدم تحمل جهاز المدينة تكلفة الغاز سوا تكلفة المحطة

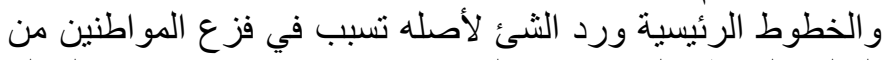

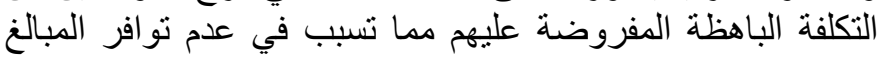

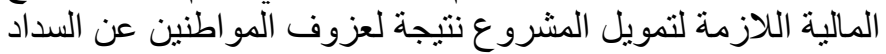

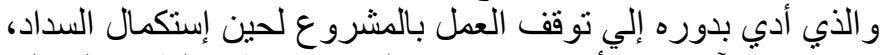

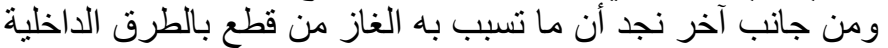

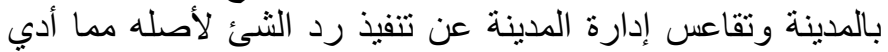
إلي ظهور المدينة بشكل غير لائق وتضرر المو اطنين من ذللك.

\section{ب- ق قطاع الخدمات}

تتنوع الخدمات الموجودة بمدينة المنيا الجديدة لتلبية احتياجات

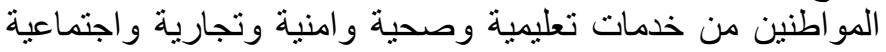
وترفيهية.

الخدمات العامة

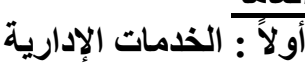

مبنى جهاز تنمية مدينة المنيا الجديدة، مبنى إدارة الحماية المدانية المدية،

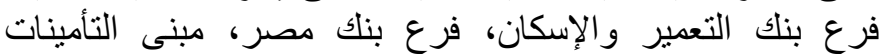

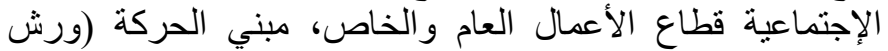

\section{تانيا : الخدمات الإجتماعية}

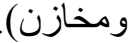

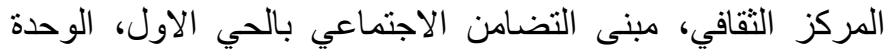

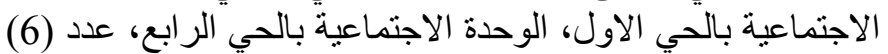

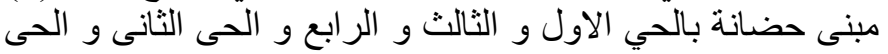
السادس ومنطقة الإمتداد (840 فدان)، دار ايتام ودار مسنين (مدينة الران

ثُالثا : الخذمات التموينية
تم تنفيذ شبكة التليفونات للأحياء ( الأول بعدد 8000 خط خط بعات

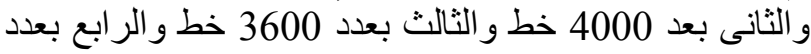

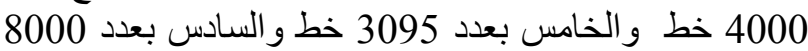
خط و الحرفى بعدد 4000 خط ) و وابنى بيتك (1) بعد (1) بعدد 1059

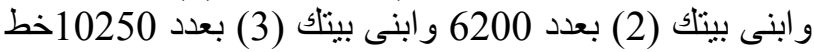

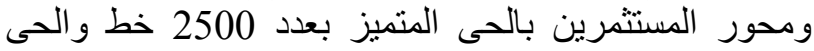

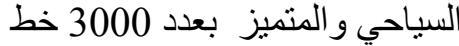
تم تنفيذ شبكة الإتصالات لعدد (128) عمارة إسكان إجتماعى بمنطقة 840 فدان . تصن تم تنفيذ شبكة تليفونات مر اكز الاحياء و الترفيهي بعدد 1600

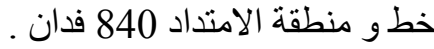
إجمالى اطو ال الثبكات المنفذة 401 كم

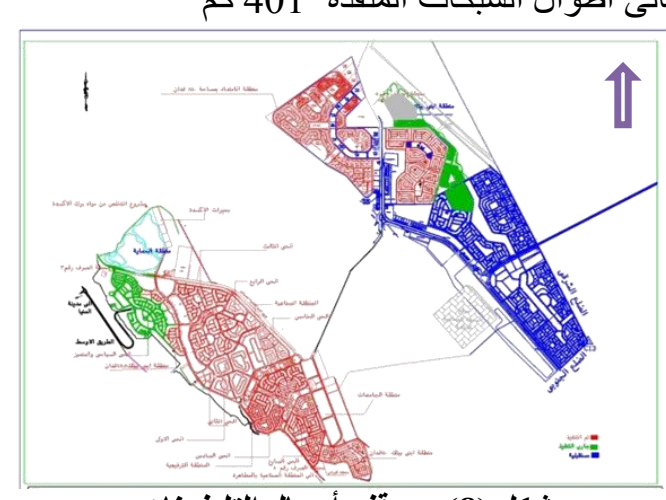

شكل (8): موقق أعمال التليفونات

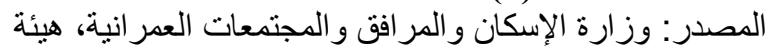
المجتمعات العمر انية الجديدة، مركز الإعلومات، مخططات المدن الجديدة وموقف الار اضي مزي

سادساً: الطرق

تم تنفيذ شبكات طرق على مستوى المدينة للأحياء (الأول

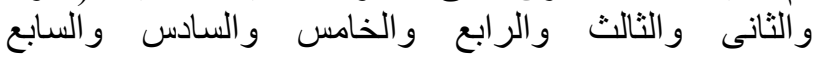

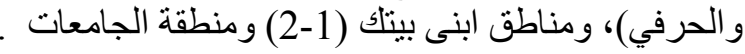

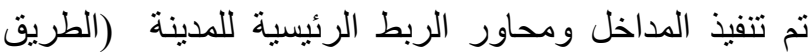

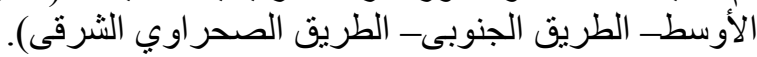

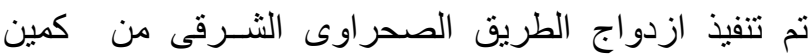
الصفا حتى المرور (مرحلة أولى).

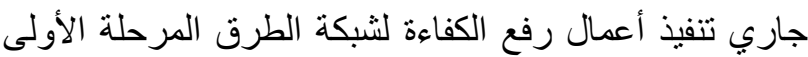

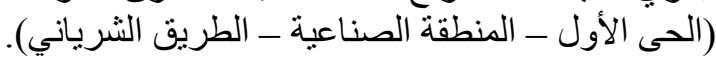

تم تتفيذ أرصفة الأحياء ( الثاني و الثالث و الخامس ).

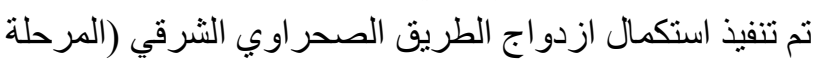

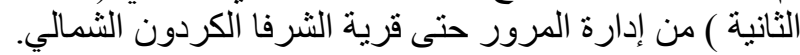
جارى تنفيذ أعمال الاسفلت بالنسبة للفرمة بعد انتهاء أعمال الثبكات لمنطقة النوادي و الحي السياحي و المتميز.

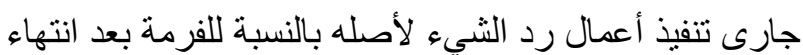
أعمال الثبكات لمنطقة الامتداد 840 فدان ( نسبة الإشغال لا لأن

تتعدى 70 \% \% ).

تم تنفيذ الطرق لمجاورتي الإسكان القومي بمنطقة الامتداد 840 فدان ، منطقة ابنى بينك 400 فدان . تم تنفيذ طرق 140 فدان إسكان اجتماعي ( مرحلة أولى ) ضمن أمر إسناد مر افق ( شبكات مياه - صرف ـ ـ كهرباء ). 
- مدرسة الحرية الإعدادية بنين (الحى الأول)

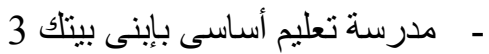

- المدرسة الإعدادية و الثانوية بنات الجديدة بمركز خدمات بين بين الحى الثانى و الثالث: الإعد

- - مدرسة تعليم أساسى بمنطقة الإمتداد (840 فدان)

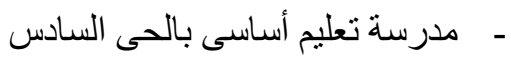

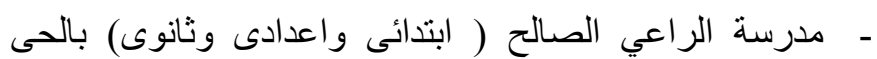
الاول مدرن.

- مدرسة المنارة (ابتدائى واعدادى وثانوى ) بمركز الحى

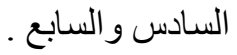

- مدر المدة المصرية الألمانية .

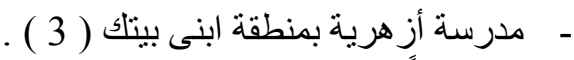

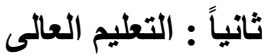

- تم تتفيذ وتشغيل فرع كلية الآداب جامعة المنيا

- كلية طب بيطري جامعة المنيا

ـ - أكاديمية السادات للعلوم الإدارية

- تم تتفيذ عدد (2) كلية بجامعة در اية وجارى استكمال الباقي - تم إفتتاح عدد (4) كليات للأزهر الثريف للبنات بالمعهد الأز هري

$$
\begin{aligned}
& \text { - تم تخصيص جامعة خاصة (اللوتس) بالامتداد } \\
& \text { ثالثا : مراكز علمية } \\
& \text { - المركز الاستكثافي للعلوم، } \\
& \text { - - مركز تطوير تكنولوجي ومركز تدريب الكهرباء. } \\
& \text { قطاع الخدمات الصحية نطوية } \\
& \text { أولاً : المستثَفيات المشية } \\
& \text { - مستشفى } 24 \text { سرير بالحي الاول . } \\
& \text { - - مستشفى } 150 \text { سرير بمركز المدينة . } \\
& \text { ثانيا : المراكز الطبية }
\end{aligned}
$$

- مركز طبي بالحى الأول، مركز طبي بالحي الرابع، مركز طب البه

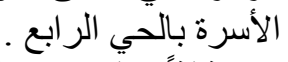

ثالثاً : الوحدات الوحية الصية

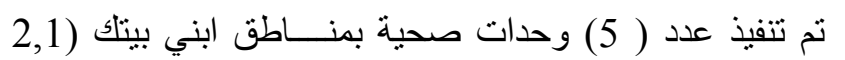

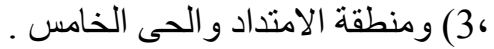

- تم تنفبذ مبنى اسعاف بالحى السابع .

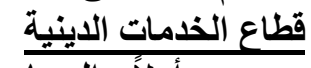

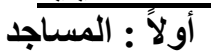

- تم تنفيذ عدد(4) مساجد بالحي الأول وعدد(3) مساجد بالحي

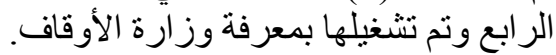

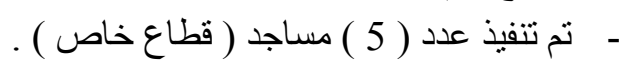$$
\text { - - }
$$

- تم تخصيص ار اضى لعدد 7 مساجد .

$$
\text { ثانيا : الكنائس }
$$

- تم تنفيذ كنيسة للأقباط الارثوذكس بالحي الاول.

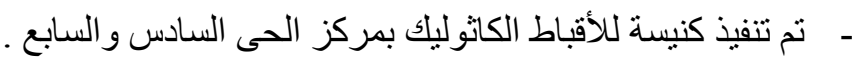

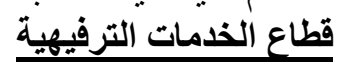

مبنى مركز توزيع البوتاجاز ، عدد (2) مخبز بلدي، عدد (2) مخبز

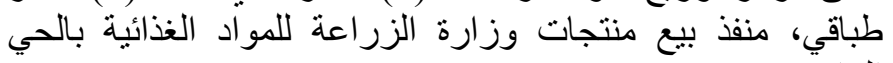

رابعا : الخدمات التجارية

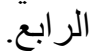

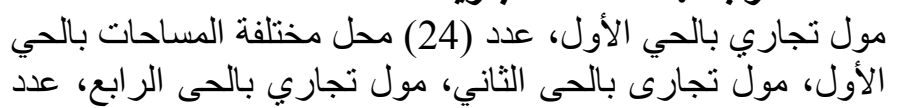

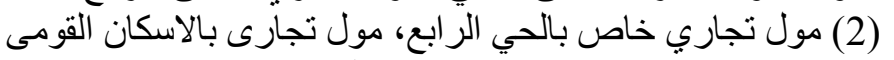

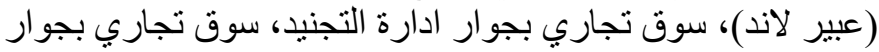

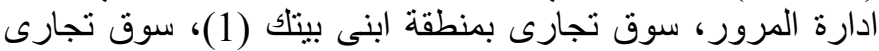

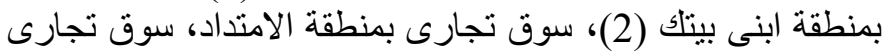

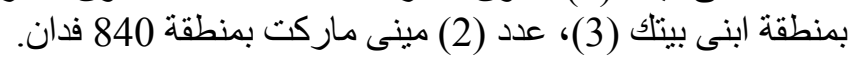

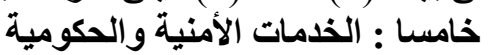

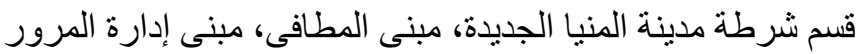

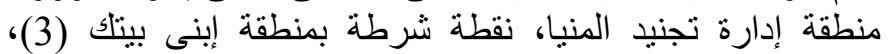
بو ابات أمنية بمدخل المدينة الثرقي.

\section{سادسا : خدمة المواصلات}

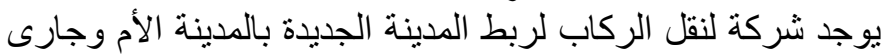

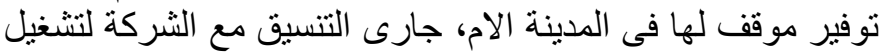

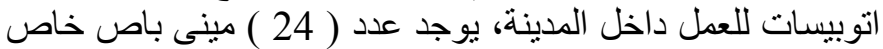
سعة ( 22 ) راكب لنقل الركاب من المنيا الام الى منطقة التجنيد

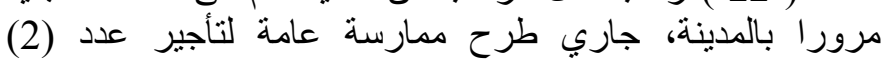
اتوبيس.

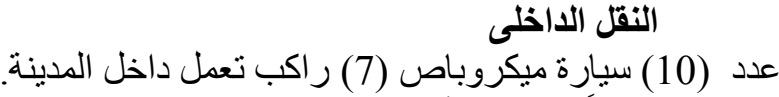

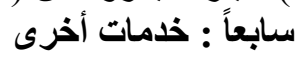

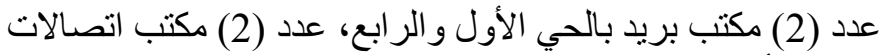

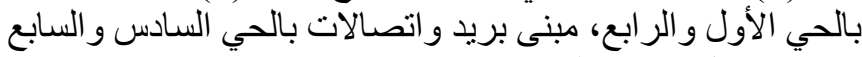

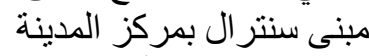

أولاً : التّعليم الأساسى والثانوى

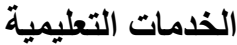

- مدرسة تعليم أساسى بالحى الأول (مبارك سابقاً) - مدرسة تعليم أساسى بالحى الرابع (شباب التحرير الإبتدائى) - مدرسة تعليم أساسى بإبنى بيتك 1 -

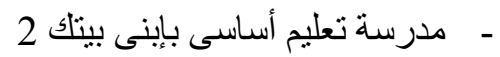
- مدرسة ثانوى بمركز المدينة

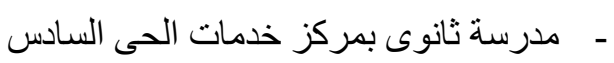

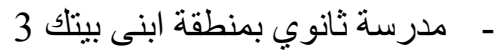

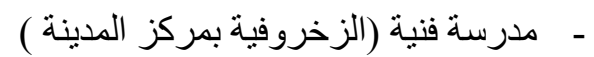
- - مدرسة ثانوى صناعى (بالمنطقة الصناعية بة) - - المدرسة الفندقية (منطقة الجامعات) - - مدرسة إعدادى وثانوى رياضى بالحى الأول (بنين) - - مدرسة تعليم فنى (مبارك كول) بمنطقة الجامعات - - المدرسة العسكرية الرياضية (منطقة الجامعات) 
Vol. 41, No.2. July 2022

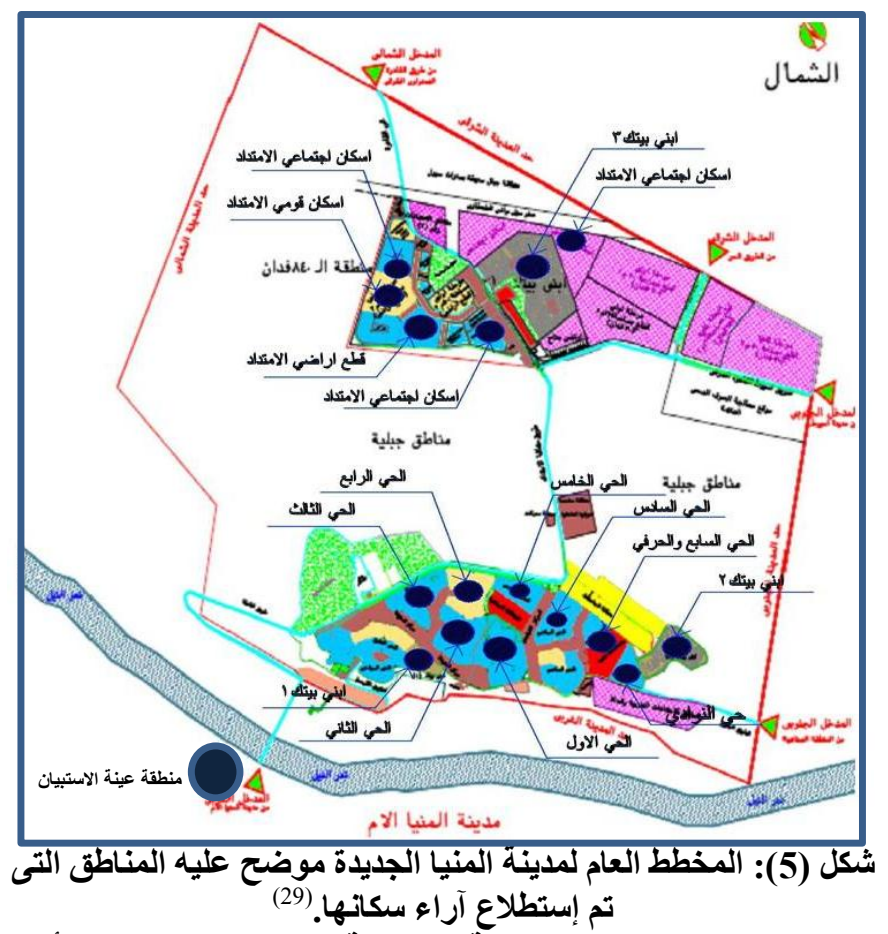

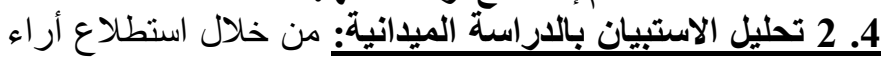

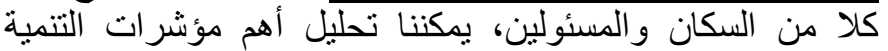

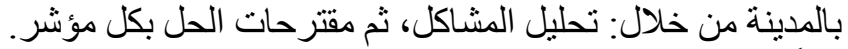
أولاً: مؤشر عن تات عامة بالنسبة لأسباب إنتقال العينة (النى تم إستطلاع رأيها) إلى إنى

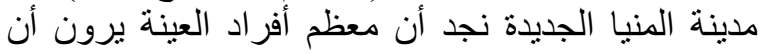

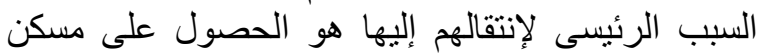

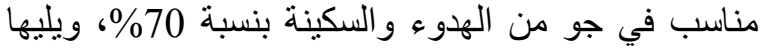
هدف وجود بيئة أفضل للمعيشة والحئة الحصول على فرصة

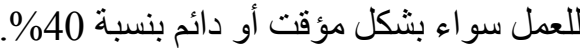

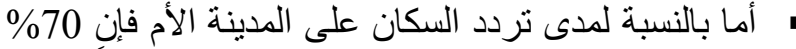
من العينة يترددون على مدينة المنيا الأم يومياً، بينما

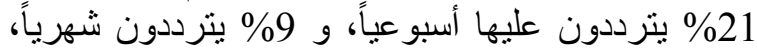
مما يوضح إرتباط السكان بالمدينة الأم وعدم إكتفائها الذاتي. ثنانياً: مؤشر ات بيئية تحليل المشكلة: • بإستبيان السكان عن المشاكل البيئية التي يعانون منها بمدينة

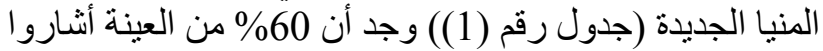
إلي وجود العديد من تلك المشاكل.

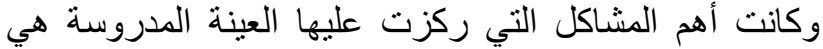

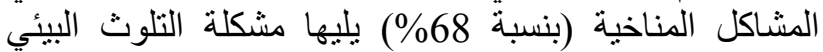

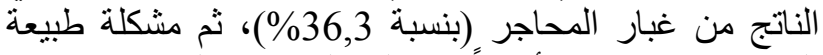

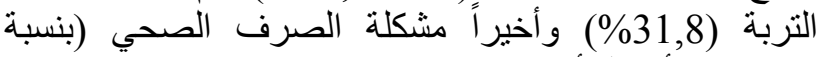

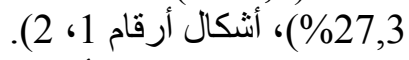

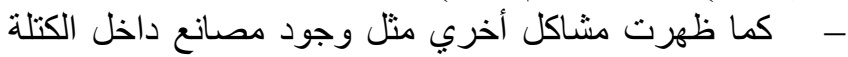

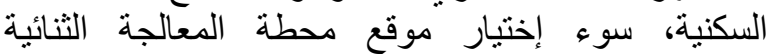
(بحيرات الأكسدة) في شمال المدينة، إنتشار الحشرات التشات الثرات بكثافة و الحيو انات مثل (النموس- النمل- الكلاب).

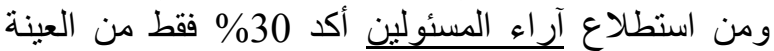

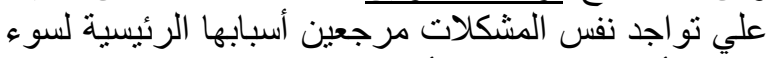

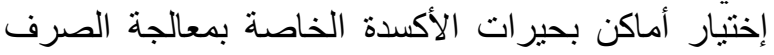

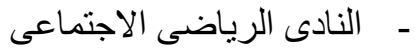

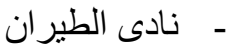

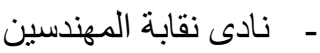

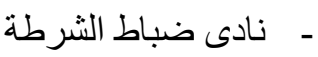

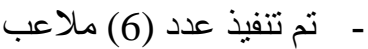

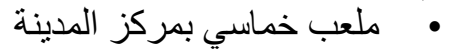

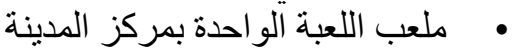

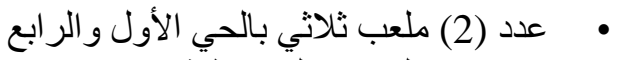

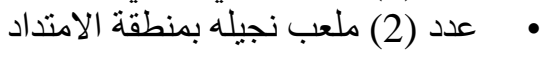

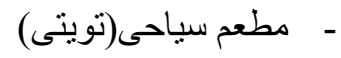
- مركز تنمية رياضية، حدائق عامة.

وقد يظهر من التحليل السابق أن مدينة المنيا الجديدة يوجد ما يكفيها

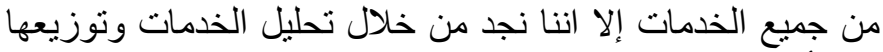
علي أحياء المدينة لا تكفي إحنياجات السكان.

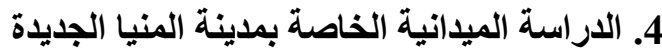

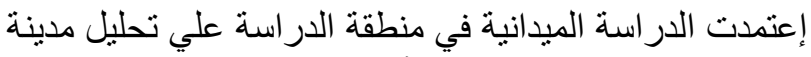
المنيا الجديدة عن طريق إستطلاع آراء السكان بالئلة المدينة من خلال

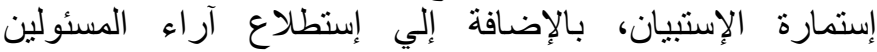
و المتخصصين حول مدي تحقيق معايير ومؤشر ات التنمية بالمدينة.

4. 1 الإعتبارات التى تم مراعاتها فى تصميم إستمارة الإستبيان 1. إنتملت الأسئلة علي عدة أقسام وذلك للتوصل إلي معرفة إلتة

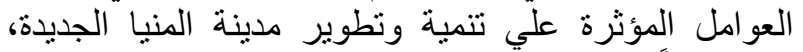

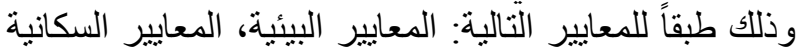

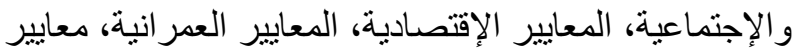
البنية الأساسية، معايير إدارية وسياسية. 2. معظم الأسئلة وضعت في في صورة إختيار اتلة لجعل إجابات

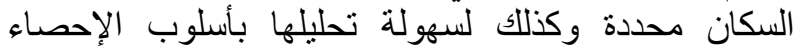

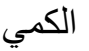
3. إتاحةً الفرصة أمام العينة المبحوثةــ من خلال بعض الاسئلة.

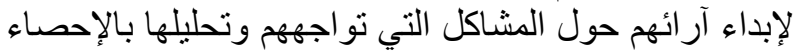
الكيفي. 4. وقد إعتمدت الدراسة علي البيانات التي تم جمعها ميدانياً

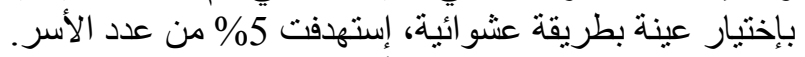

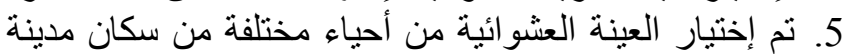
المنيا الجديدة وإستطلاع آرائهم من خلاءل إستمارة الإستيبان

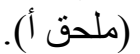

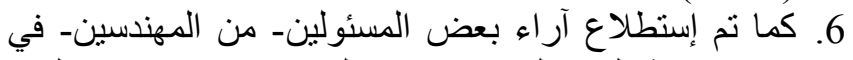

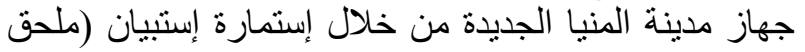

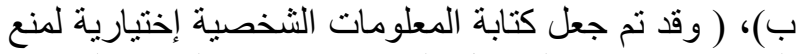

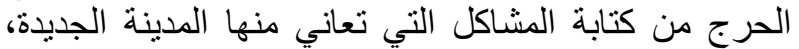
ولمر اعاة الدقة قدر الإمكان في كتابة البيانات في الإستمارة (الخاصة بهم). 7. وقد أجريت الدراسة في الفترة الزمنية من شهر يناير إلى

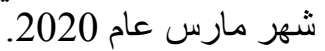




\section{Vol. 41, No.2. July 2022}

المنزل، وقد رأي 9,1\% من العينة وجود مشاكل آخري منمثلة في

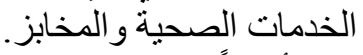

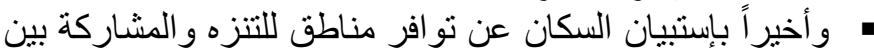

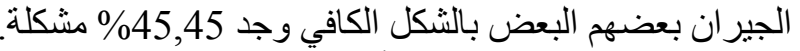

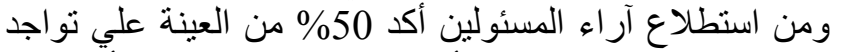

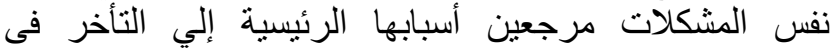

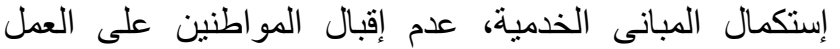
بالمدينة، الإنتظار لإكتمال عدد السكان بالمدينة، تخطيط مر اكز المزي

الخدمات غير مناسب. الإنمان.

جدول رقم (2): آراء السكان حول مدي توافر الخدمات بالمدينه

\begin{tabular}{|c|c|c|c|c|c|c|}
\hline \multicolumn{3}{|c|}{ مدي الرضي عن قـربهـا من المنزل } & \multirow[b]{2}{*}{ توحاً إلي } & \multirow[b]{2}{*}{ ل الا توجد } & \multirow[b]{2}{*}{ توجد } & \multirow[b]{2}{*}{ الخدمة } \\
\hline إلي حداً & مرضير & 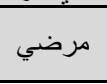 & & & & \\
\hline$(\% 13.2)$ & $(\% 50)$ & $(\% 35.8)$ & $(\% 9.1)$ & $\begin{array}{c}\% 45.45) \\
(\end{array}$ & $\begin{array}{c}45.45) \\
(\%\end{array}$ & إداري \\
\hline$\% 27.27)$ & $\% 45.46)$ & $\begin{array}{c}027.27) \\
(\end{array}$ & $(\% 18.2)$ & $(\% 31.8)$ & $(\% 50)$ & 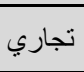 \\
\hline$(\% 25.2)$ & $\begin{array}{c}\% 27.35) \\
(\end{array}$ & $\begin{array}{c}\% 47.45) \\
(\end{array}$ & $(\% 18.2)$ & $\begin{array}{c}\% 31.82) \\
(\end{array}$ & $(\% 50)$ & د د \\
\hline $\begin{array}{c}\% 36.26) \\
(\end{array}$ & $\begin{array}{c}\% 31.56) \\
(\end{array}$ & $\begin{array}{c}\% 32.18) \\
(\end{array}$ & $(\% 18.2)$ & $\begin{array}{c}\% 36.36) \\
(\end{array}$ & $\begin{array}{c}45.45) \\
(\%\end{array}$ & تعليمي \\
\hline $\begin{array}{c}\% 16.83) \\
(\end{array}$ & $\begin{array}{c}\% 25.63) \\
(\end{array}$ & $\begin{array}{c}\% 57.54) \\
(\end{array}$ & $\begin{array}{c}\% 20.18) \\
(\end{array}$ & $(\% 23.8)$ & $\begin{array}{c}45.90) \\
(\%\end{array}$ & الأمن \\
\hline & & & 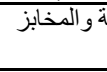 & دامات الصد\%) & متمثلة & 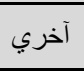 \\
\hline
\end{tabular}

جدول رقم (3): آراء السكان حول مدي توافر مناطق للتنزه

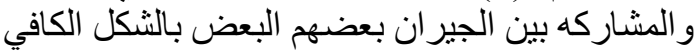

\begin{tabular}{|c|c|c|}
\hline يوجد إلي حداً ما & لا يوجد & يوجد \\
\hline$(\% 9.55)$ & $(\% 45.45)$ & $(\% 45.45)$ \\
\hline
\end{tabular}

ب- مقترحات الحل:

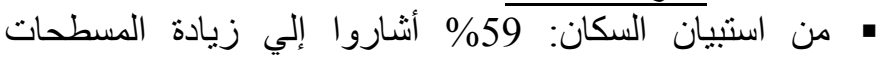

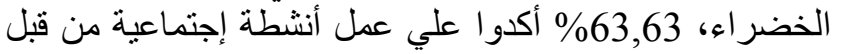
جهاز المدينة، 63,63\% عمل حدائق عامة.

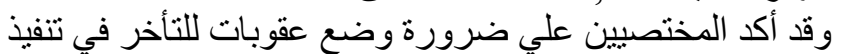

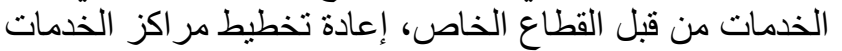
بما يخدم احتباجات السكان.

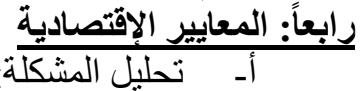

هإستبيان السكان عن مشاكل التمويل و الاستثمار ات بمدينة المنيا الجديدة (جدول رقم (4، 5، 6، 7، 8، 9)) وجد أن 64\% من من العينة غير راضي عن حجم ونوع الاستثمار ات بالمدينة، كما ولات

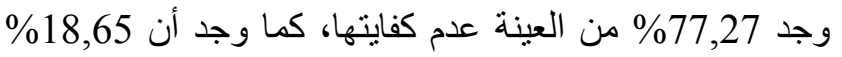
من العينة أشاروا إلي عدم وجود عناصر لجذب الاستثمار بالمدينة.

- وكانت أهم اسباب جذب الاستثمار من وجهة نظر العينة المدروسة هي موقع المدينة (بنسبة ابت الابنة عن النيل (بنسبة 1,831\%)، ثم مستوي السكان ومناسبة الفئة المستهدفة (بنسبة \%1,8\%)، وجاءت التسهيلات الإدارية بنسبة منخفضة (بنسبة 13,63\%)، و اخيراً أسعار الأر اضي (بنسبة 1,831, ).

كما ظهرت مشكلة أخري التي تقلل من جذب الاستثمار بالمدينة وهي مشكلة قيود الارتفاعات المفروضة علي البناء.
الصحي في الثمال بما يسبب مشاكل بيئية مع إتجاه الرياح و الرو ائح و الملوثات المُّات

جدول رقم (1): آر اء السكان حول مدي تو اجد مشاكل بيئية

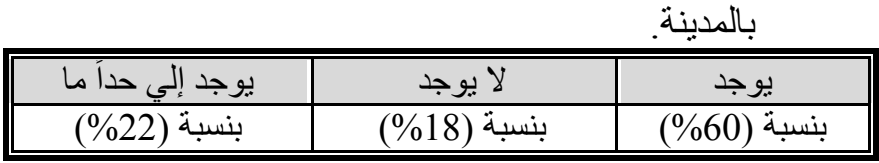

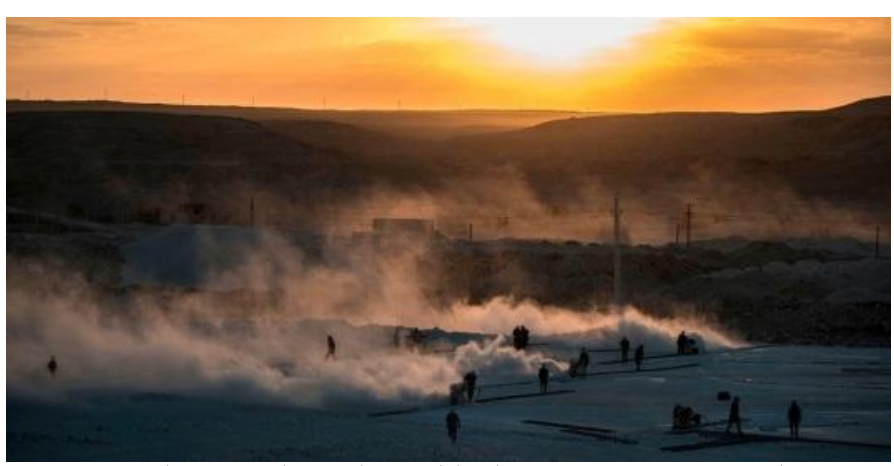

شكل رقم (6): يوضح مشكلة التلوث بالغبار الناتج من المحاجر

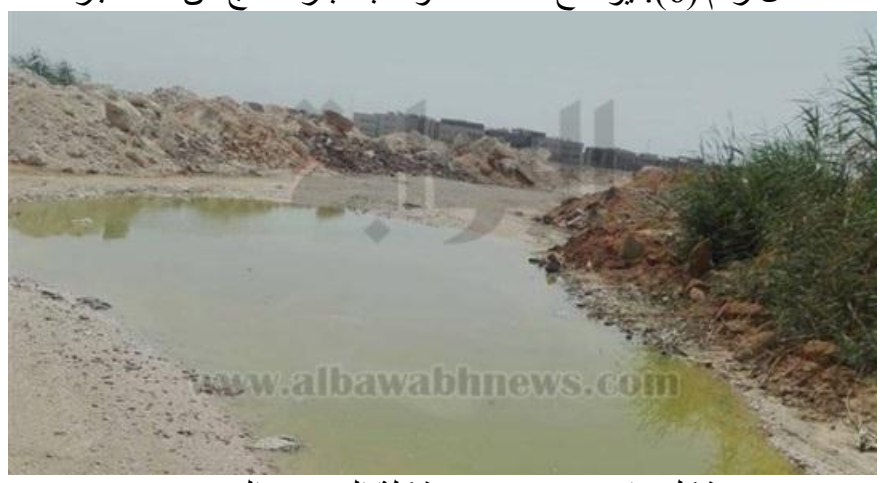

شكل رقم (7): يوضح مشكلة الصرف الصحي

ب- مقترحات الحل:

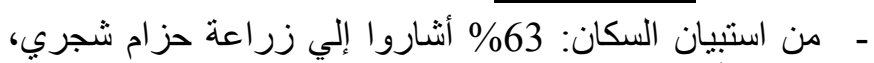

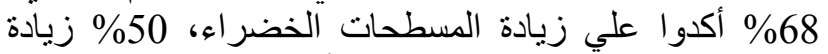

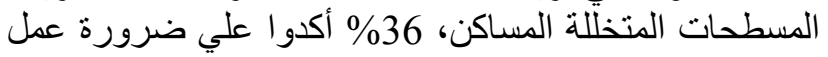
محطات معالجة ثلاثية، ومقترحات آخري متمثلة في (تشجير المير

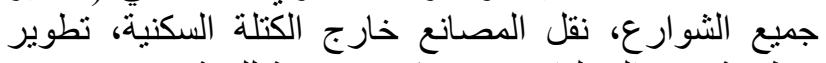
منظومة جمع المخلفات بحيث تكون صديقة للبيئة). - وقد أكد المختصيين علي ضرورة نقل محطة المعالجة الثنائية (بحير ات الأكسدة) من شمال المدينة.

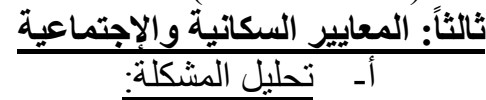

بإستبيان السكان عن المشاكل السكانية التي يعانون منها بمدينة المنيا الجديدة (جدول رقم (2، 3)) وجد أن 45,45\% من الني العينة أشناروا

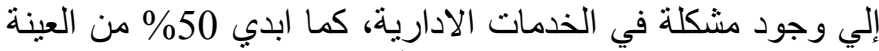

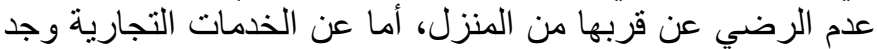

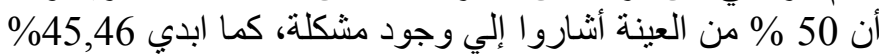

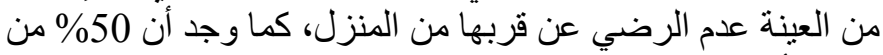

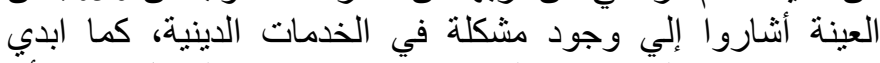

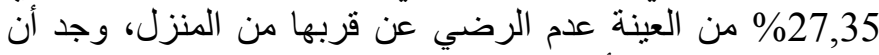

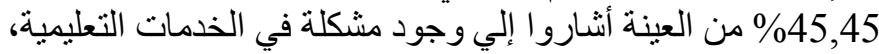

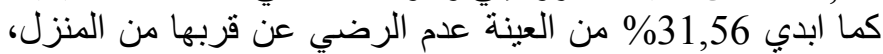

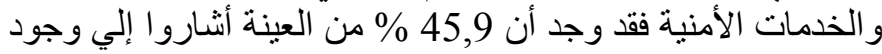
مشكلة، كما ابدي 25,63\% من العينة عدم الرضي عن عن قربها من 


\section{Vol. 41, No.2. July 2022}

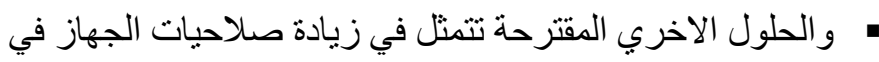

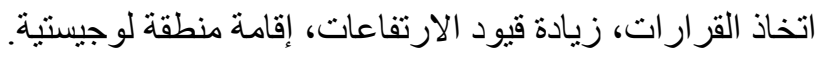
وقد أكد المختصين علي ضرورة زيادة صلاحيات الجهاز في التئي

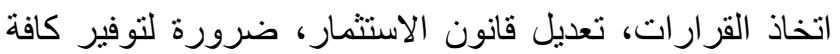
مجالات فرص العمل، وخصوصاً فى مجال الصناعة حيث التها أنها تستو عب العديد من العمالة، بالإضافة إلى إنشاء الورش الحردات الحرفية و المكاتب الهندسية و المصالح الحكومية و الجامعات.

\section{خامساً: المعاييز العمرانية أ- تحليل المشكلة:}

بإستبيان السكان عن المشاكل العمرانية بمدينة المنيا الجديدة (جدول رقم (10، 11، 12، 13)) وجد أن الن النيان \%54,54 من العينة أن المسافة بين المنزل و والعمل بعيدة

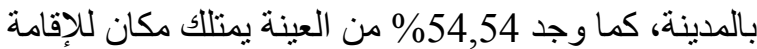
بالمدينة ومنها 45,45\% يمنالك وحدة سكنية، وكانة وكان

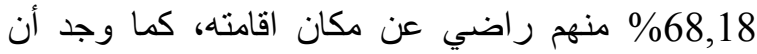

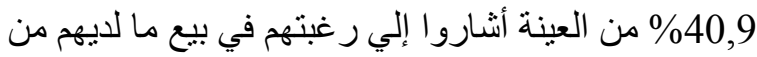

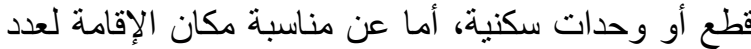

أفر اد الأسرة فقد وجد 31,81\% عدم مناسبتها.

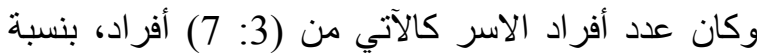
\% \% لمتوسط حجم الاسرة 3 أفر اد، بنسبة 4.5\% (75) لمتوسط

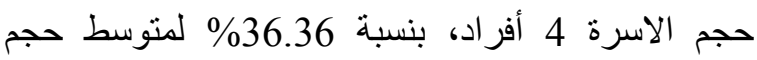
الاسرة 5 أفراد، بنسبة 40.9\% لمنوسط حجم الاسرة 6

أفر اد، بنسبة 9\% لمتوسط حجم الاسرة 7 أفر اد. و اتضح من الاستبيان أن بعض السكان تقطن بالمدينة منذ (2019:2001) وكانت أهم المشاكل من وجهة نظر العينة المدروسة هي عدم تو افر الخدمات (بنسبة 36,36\%) يليها عدم تو افر الفر

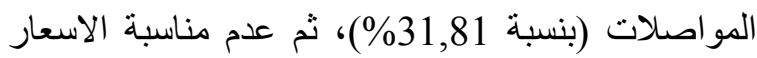
(بنسبة 31,81\%)، وأخيراً بعد السكن عن العمل (بنسبة

.$(\% 27,27$

وكانت اراء السكان حول مدي ملائمة إختيار موقع المدينة

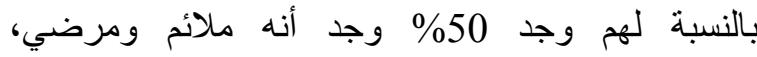

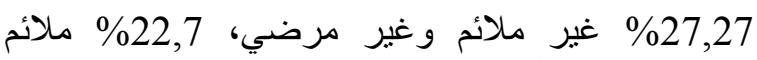

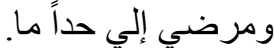
ومن استطلاع آراء المسئولين حول مدى ملى ملائمة إختيار موقع المدينة فإن 50\% يرى أنه مناسب وذلإس الك بسبب: قرب مدينة المنيا الجديدة من المدينة الأم ـ قربها من لئن

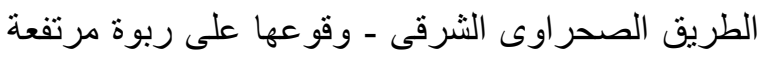
مما يوفر منظر جمالى - بعيدة عن الرقعة الزراعية، بينما

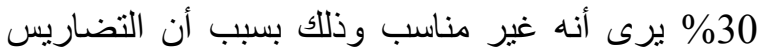

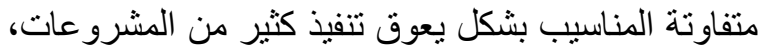

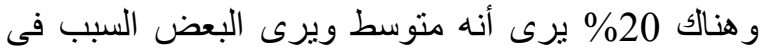
ذلك أن إمكانية التوسع صعبة. جدول رقم (10): آراء السكان حول المسافة بين المنزل و العمل
من خلال إستطلاع آراء عينة السكان عن اسعار الاراضي إنهاء

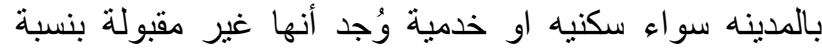
59\%، و اسعار الار اضي بمنطقة الامتداد بالمدينة سو اء سكنية أهية

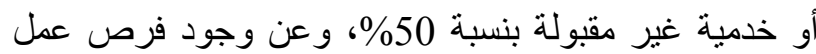

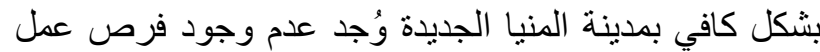
بنسبة 68,18\% ومن استطلاع آراء المسئولين أكد 20\% فقط من العينة علي

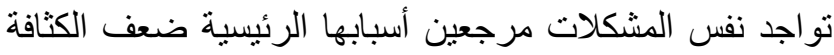

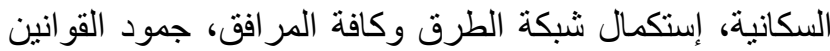

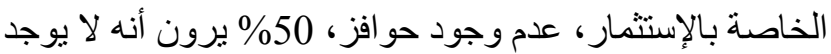

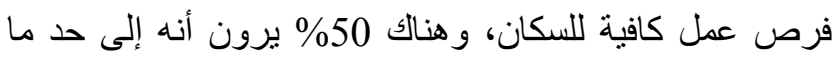

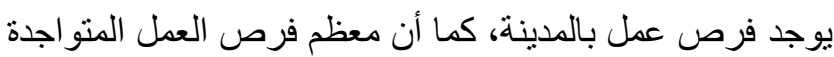
بالمدينة هى فئة العمالة. جدول رقم (4): آراء السكان حول مدي الرضا عن حجم ونوع

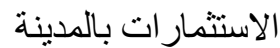

\begin{tabular}{|c|c|c|}
\hline مرضي إلي حداً ما & غير مرضي & مرضي \\
\hline$(\% 27)$ & $(\% 64)$ & $(\% 9)$ \\
\hline \multicolumn{3}{|c|}{ جدول رقم (5): آر اء السكان حول مدي كفايتها } \\
\hline كافي إلى حداً ما & غبر كافى & كافي \\
\hline$(\% 13.63)$ & $(\% 77.27)$ & $(\% 9.1)$ \\
\hline
\end{tabular}

الاستثمار بالمدينة

\begin{tabular}{|c|c|c|}
\hline يوجد إلي حداً ما & لا يوجد & يوجد \\
\hline$(\% 40.9)$ & $(\% 18.65)$ & $(\% 40.45)$ \\
\hline
\end{tabular}

جدول رقم (7): اسعار الار اضي بالمدينه سواء سكنيه او خدمية:

\begin{tabular}{|c|c|c|}
\hline غير مقبولة & مقبولة إلي حداً ما & مقبولة \\
\hline$(\% 59)$ & $(\% 19.28)$ & $(\% 21.72)$ \\
\hline
\end{tabular}

جدول رقم (8): اسعار الاراضي بمنطقة الامتداد بالمدينة سواء

\begin{tabular}{|c|c|c|}
\hline غير مقبولة & مقبولة إلي حداً ما & 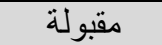 \\
\hline$(\% 50)$ & $(\% 31.81)$ & $\begin{array}{l}(\% 18.18) \\
\end{array}$ \\
\hline
\end{tabular}
جدول رقم (9): فرص عمل بشكل كافي بالمدينة

\begin{tabular}{|c|c|c|c|}
\hline أسباب عدم وجودها & لا توجد & \multicolumn{2}{|c|}{ توجد } \\
\hline 口 لعدم وجود إستثمار ات بالمدينة بنسبة & & دائمة & مؤقتة \\
\hline 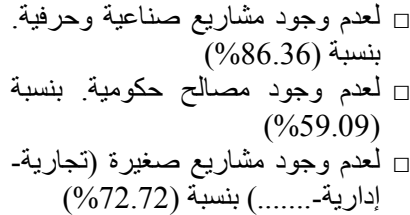 & $(\% 68.18)$ & $\begin{array}{c}\% 21.72) \\
(\end{array}$ & $\begin{array}{c}\% 59.09) \\
(\end{array}$ \\
\hline
\end{tabular}

ب- مقترحات الحل:

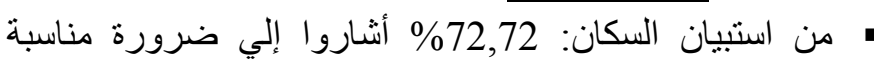
الأسعار، 54,54\% أكدوا علي توفير المرافق، 81,81\% \%

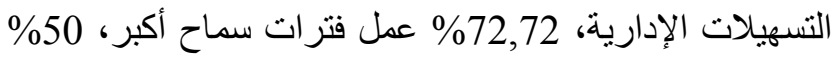
قرب المناطق المقترحة من السكان، 81,81\% نوفير الخدمات

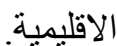


Vol. 41, No.2. July 2022

وسيلة المواصلات المستخدمة وكانت النتيجة (خاصة

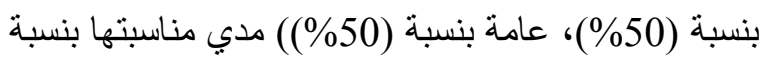
\% 27,27 غبر مناسبة. \% \%

جدول رقم (14): آراء السكان حول حول وجود صعوبة في طبيعة الأرض أندوض

\begin{tabular}{|c|c|c|}
\hline توجد إلي حداً ما & لا توجد & توجد \\
\hline$(\% 13.63)$ & $(\% 4)$ & $(\% 81.81)$ \\
\hline
\end{tabular}

جدول رقم (15): آراء السكان حول وجود مشكلة في الإتصال بين المدينة الجديدة و المدينة الأم

\begin{tabular}{|c|c|c|}
\hline توجد إلي حداً ما & لا توجد & توجد \\
\hline$(\% 13.63)$ & $(\% 45.45)$ & $(\% 40.9)$ \\
\hline
\end{tabular}

جدول رقم (16): آر اء السكان حول وجود مشكلة في المر افق (مياه،

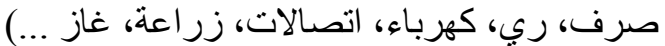

\begin{tabular}{|c|c|c|c|c|c|c|c|c|}
\hline آخر & غاز & زرة & اتصالا & كهربا & ري & صن & مياه & المر \\
\hline $\begin{array}{c}) \\
27.2 \\
(\% 7\end{array}$ & $\begin{array}{c}\text { ) } \\
86.6 \\
(\% 3 \\
\end{array}$ & $\begin{array}{c}) \\
54.5 \\
(\% 4\end{array}$ & $\begin{array}{c}) \\
36.36 \\
(\% \\
\end{array}$ & $\begin{array}{c}) \\
13.6 \\
(\% 3\end{array}$ & $\begin{array}{c})^{\prime} \\
68.18 \\
(\% \\
\end{array}$ & $\begin{array}{c})^{2} \\
27.2 \\
(\% 7 \\
\end{array}$ & $\begin{array}{c}\% 9.1) \\
(\end{array}$ & توجد \\
\hline $\overrightarrow{(-}$ & $\begin{array}{c})^{\prime} \\
13.6 \\
(\% 3 \\
\end{array}$ & $\begin{array}{c})^{\prime} \\
27.2 \\
(\% 7 \\
\end{array}$ & $\begin{array}{c})^{\prime} \\
45.45 \\
(\% \\
\end{array}$ & $\begin{array}{c})^{\prime} \\
72.7 \\
(\% 2 \\
\end{array}$ & $\begin{array}{c})^{\prime} \\
22.72 \\
(\% \\
\end{array}$ & $\begin{array}{c}{ }^{2} \\
68.1 \\
(\% 8 \\
\end{array}$ & $\begin{array}{c}90.9) \\
(\%\end{array}$ & توجد \\
\hline $\overrightarrow{(-}$ & $\overrightarrow{(-}$ & $\begin{array}{c}\text { ) } \\
18.1 \\
(\% 8\end{array}$ & $\begin{array}{c})^{\prime} \\
18.18 \\
(\%\end{array}$ & $\begin{array}{c}\text { ) } \\
13.6 \\
(\% 3\end{array}$ & $\begin{array}{c}9.1) \\
(\%\end{array}$ & $\begin{array}{c}4.5) \\
(\%\end{array}$ & $(\vec{c})$ & لوجالي \\
\hline
\end{tabular}

جدول رقف (17): آراء السكان حول توافر المواصلات بالثكل الكافي، بجميع الاوقات ولم الأماكن

\begin{tabular}{|c|c|c|}
\hline توجد إلى حداً ما & لا توجد & توجد \\
\hline$(\% 50)$ & $(\% 31.81)$ & $(\% 18.18)$ \\
\hline \multicolumn{3}{|c|}{ بول رقم (18): آراء السكان حول وسيلة المو اصلات المستخدمة } \\
\hline مناسبة إلي حداً ما & غير مناسبة & مناسبة \\
\hline$(\% 27.27)$ & $(\% 27.27)$ & $(\% 45.45)$ \\
\hline
\end{tabular}

ب- مقترحات الحل:

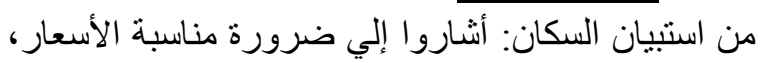

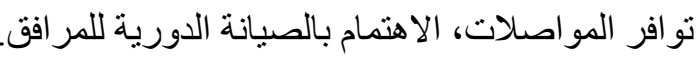

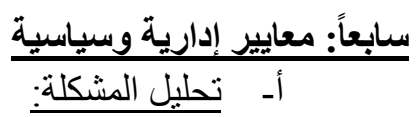

هبإستبيان السكان عن المشاكل الادارية و السياسية بمدينة المنيا

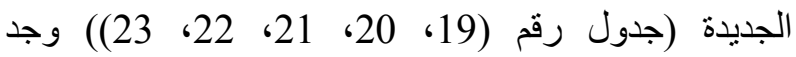
\%59,09 من العينة لديهر مشكلة في تراخيص المباني

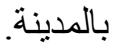
وكانت أهم المشاكل من وجهة نظر العينة المدروسة هي عدم سهولة الإجراءات من قبل جهاز المدينة (بنسبة 77,27\%)

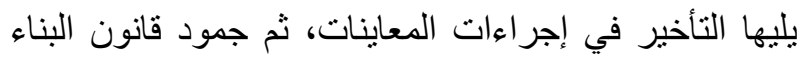
119 (بنسبة 68,18\%)، ومشاكل اخري منمثلة في مركزية

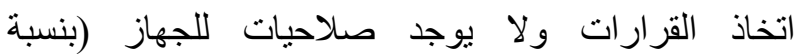
. $(\% 31,81$ وجد 86,36\% من العينة لديهم مشكلة إدارية في الجهات الإدارية بالمدينة، ورجع السبب إلي عدم تفاعل مجلس الامناء

\begin{tabular}{|c|c|c|}
\hline قريبة إلي حداً ما & بعيدة & قريبة \\
\hline$(\% 22.73)$ & $(\% 54.54)$ & $(\% 22.73)$ \\
\hline \multicolumn{3}{|c|}{ يدول رقم (11): آر اء السكان حول مدي الرضا عن مكان للإقامة } \\
\hline مرضي إلي حداً ما & غير مرضي & مرضي \\
\hline$(\% 22.73)$ & $(\% 9)$ & $(\% 68.18)$ \\
\hline
\end{tabular}

جدول رقم (12): آراء السكان حول مدي الرضا عن مناسبة مكان الإقامة لعدد أفر اد الأسرة آراه

\begin{tabular}{|c|c|c|}
\hline مناسبة إلي حداً ما & غبر مناسبة & مناسبة \\
\hline$(\% 13.63)$ & $(\% 31.81)$ & $(\% 54.54)$ \\
\hline
\end{tabular}

جدول رقم (13): آراء السكان حول مدى ملائمة إختيار موقع الددينة

\begin{tabular}{|c|c|c|}
\hline ملائم ومراً ما & غير ملائم وغير & ي \\
\hline$(\% 22.72)$ & $(\% 27.27)$ & $(\% 50)$ \\
\hline
\end{tabular}

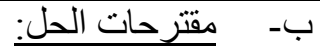

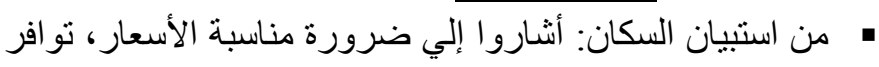

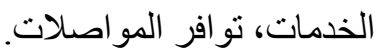

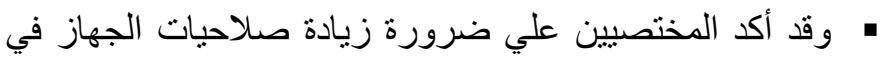

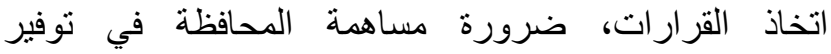

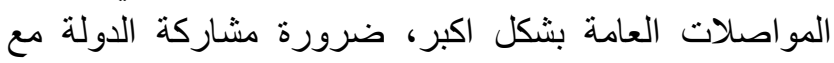
القطاع الخاص لتوفير الخدمات.

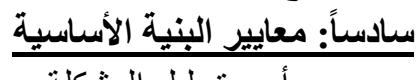

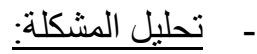

بإستيان السكان عن المشاكل بالبنية الاساسية بمدينة المنيا

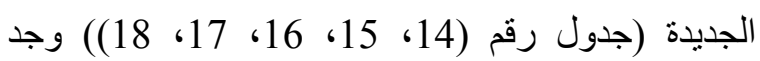

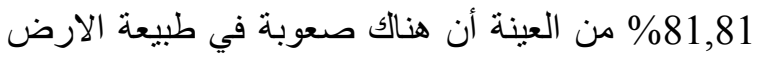
بالمدينة. وكانت أهم المشاكل من وجهة نظر العينة المدروسة هي

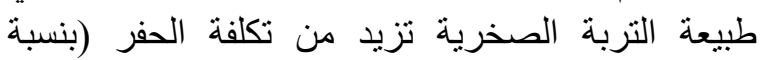

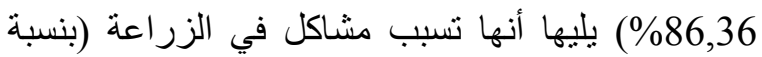
\%72,72\%)، ثم انها تتسبب في امتصاص المياه (بنسبة . $(\% 77,27$ وجد 40,9\% من العينة أن هناك مشكلة في الاتصال بين المدينة الجديدة و المدينة الأم. وكانت أهم المشاكل من وجهة نظر الأد العينة المدروسة هي

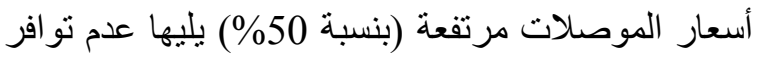

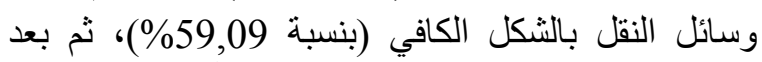
المسافة بينهم (بنسبة 31,81\%)، وأخيراً الإزدحام علي الكوبري الر ابط بينهم (بنسبة 27,27\%).

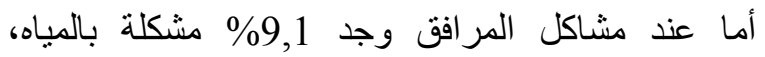

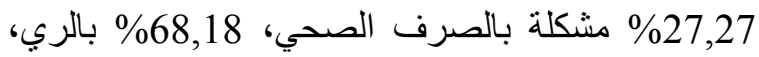

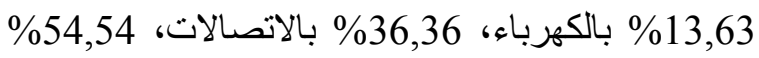

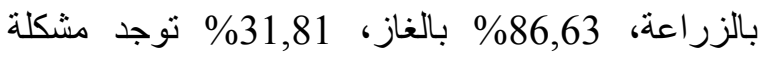
بتو افر الموصلات.

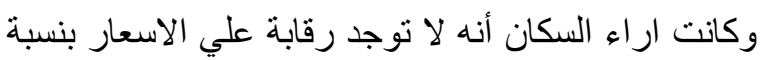

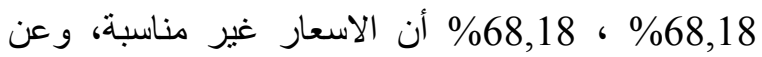


Vol. 41, No.2. July 2022

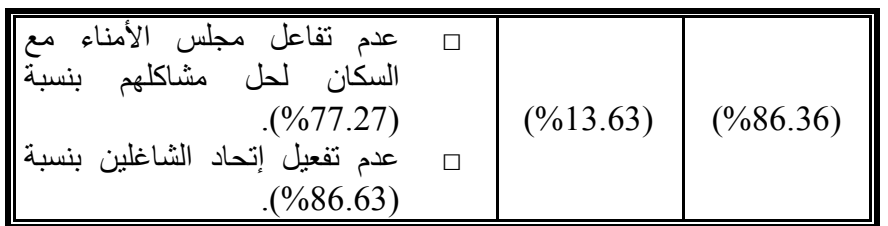

جدول رقم (21): وجد مشكلة بالنماذج المفروضة من قبل جهاز المدينة

\begin{tabular}{|c|c|c|}
\hline مناسبة إلي حداً ما & غير مناسبة & مناسبة \\
\hline$(\% 31.81)$ & $(\% 63.63)$ & $(\% 4.5)$ \\
\hline
\end{tabular}

جدول رقم (22): رأي السكان بأسلوب إدارة المدينة من حيث مشار كة السكان في تنميتها

\begin{tabular}{|c|c|c|}
\hline مناسبة إلي حداً ما & غير مناسبة & مناسبة \\
\hline$(\% 18.18)$ & $(\% 63.63)$ & $(\% 18.18)$ \\
\hline \multicolumn{3}{|c|}{ جدول رقم (23): مدي الرغبة في الإستمر ار في العيش بالمدينة } \\
\hline أرغب إلي حداً ما & لا لأرغب & 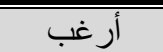 \\
\hline$(\% 13.63)$ & $(\% 36.36)$ & $(\% 50)$ \\
\hline
\end{tabular}

\section{بـ- مقترحات الحل:}

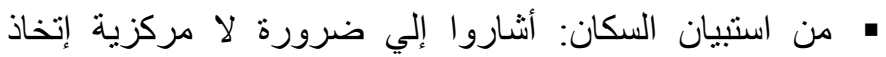
القرارات وضمان الاجر اءات المحققة لعدم التباطؤ فيها.

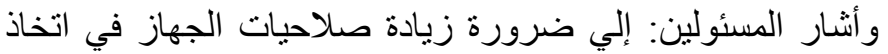

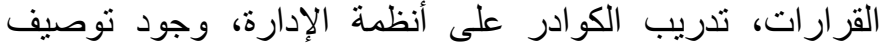

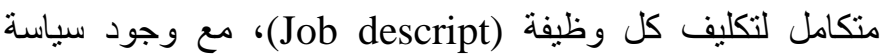
الثو اب و العقاب.

5. مؤشرات التنمية بمدينة المنيا الجديدة من الدراسة الميدانية السابقة يمكننا تلخيص أهم مؤشرات التئية التنمية

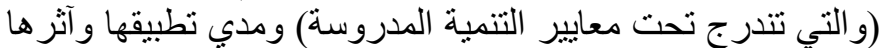
في نجاح التنمية أو فثلها بمدينة المنيا الجديدة كما يلّى.
مع السكان لحل مشاكلهم (بنسبة 77,27\%)، وكذلك عدم تفعيل إتحاد الثشاغلين (بنسبة 86,63\%)

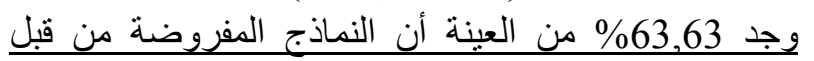

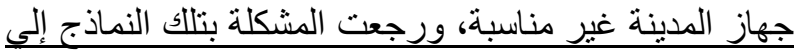
عدم تلبيتها لمنطلبات المو اطن، وكذا صغر مساحات الوحدات

وسوء تقسيمها. " وكان رأي السكان بأسلوب إدارة المدينة من حيث مشاركة

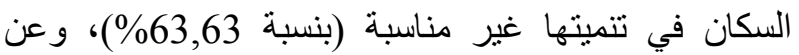
وجود من يمثلهم من السكان يوجد (بنسبة ليس علي تواصل معهم بنسبة 86,36\%، ويري بن السكان

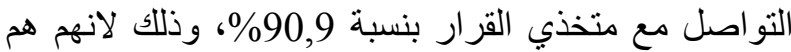

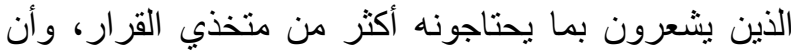
متخذ القرار ينظر نظرة عامة. هوجد أن 50\% يرغب في الاستمرار في العيش بالمدينة،

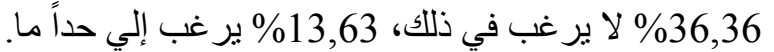

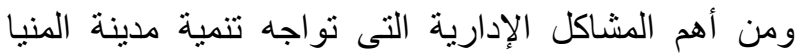

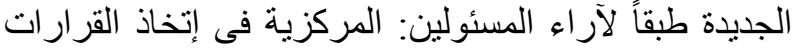

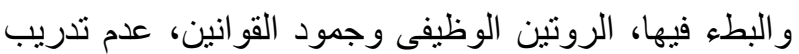

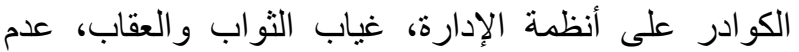
وجود نوصيف لتكليف كل وظيفة (Job descript). جدول رقم (19): آراء السكان حول وجد مشكلة في تراخيص

\begin{tabular}{|c|c|c|}
\hline توجد إلي حداً ما & لا توجد & توجد \\
\hline$(\% 31.81)$ & $(\% 9.09)$ & $(\% 59.09)$ \\
\hline
\end{tabular}

جدول رقم (20): آراء السكان حول وجود مشكلة إدارية تواجها

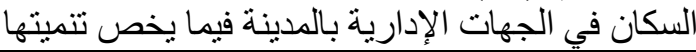

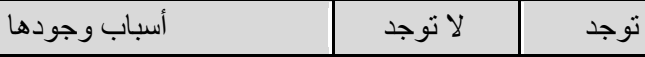

جدول (24): مدي تحقق مؤشرات التنمية التى تؤثر على تنمية المدن الجديدة فى مدينة المنيا الجديدة.

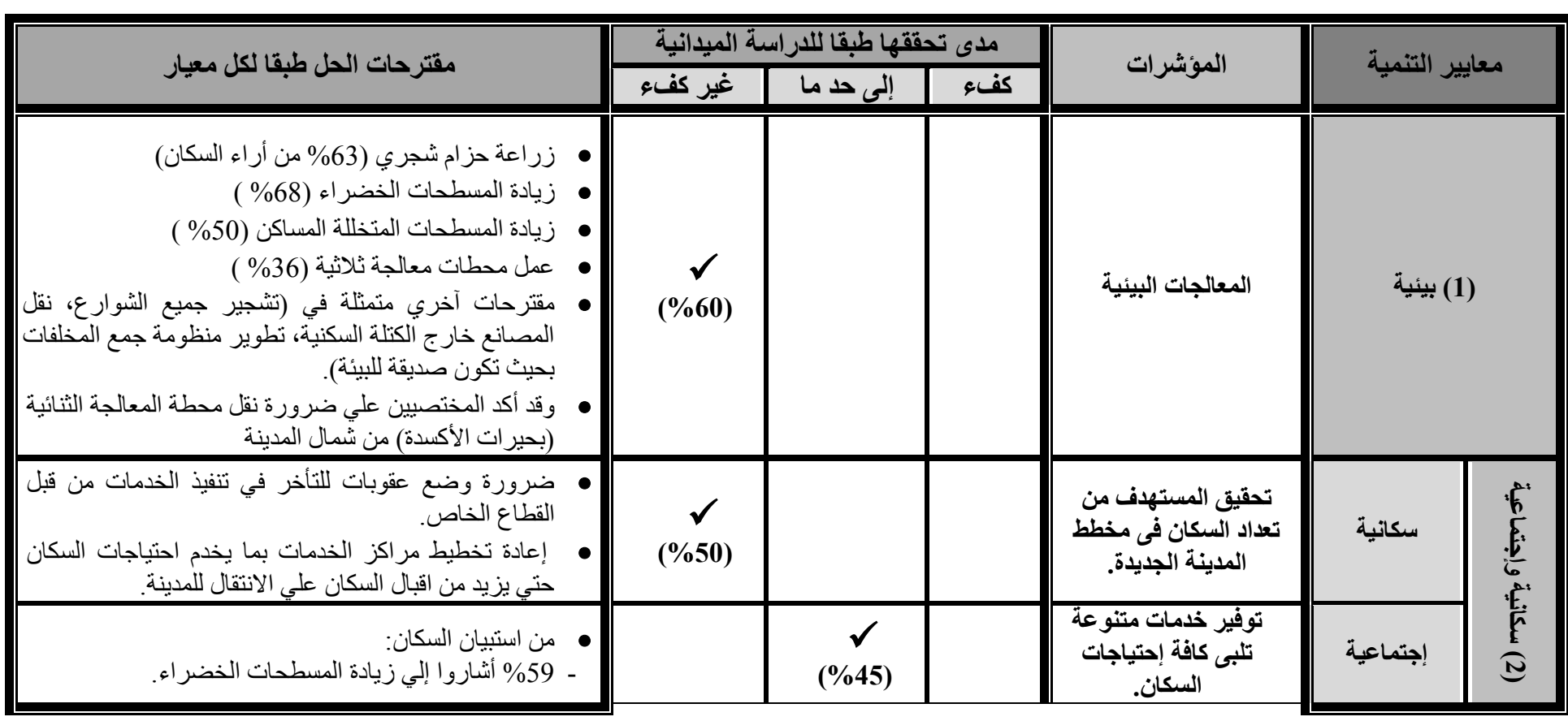


Vol. 41, No.2. July 2022

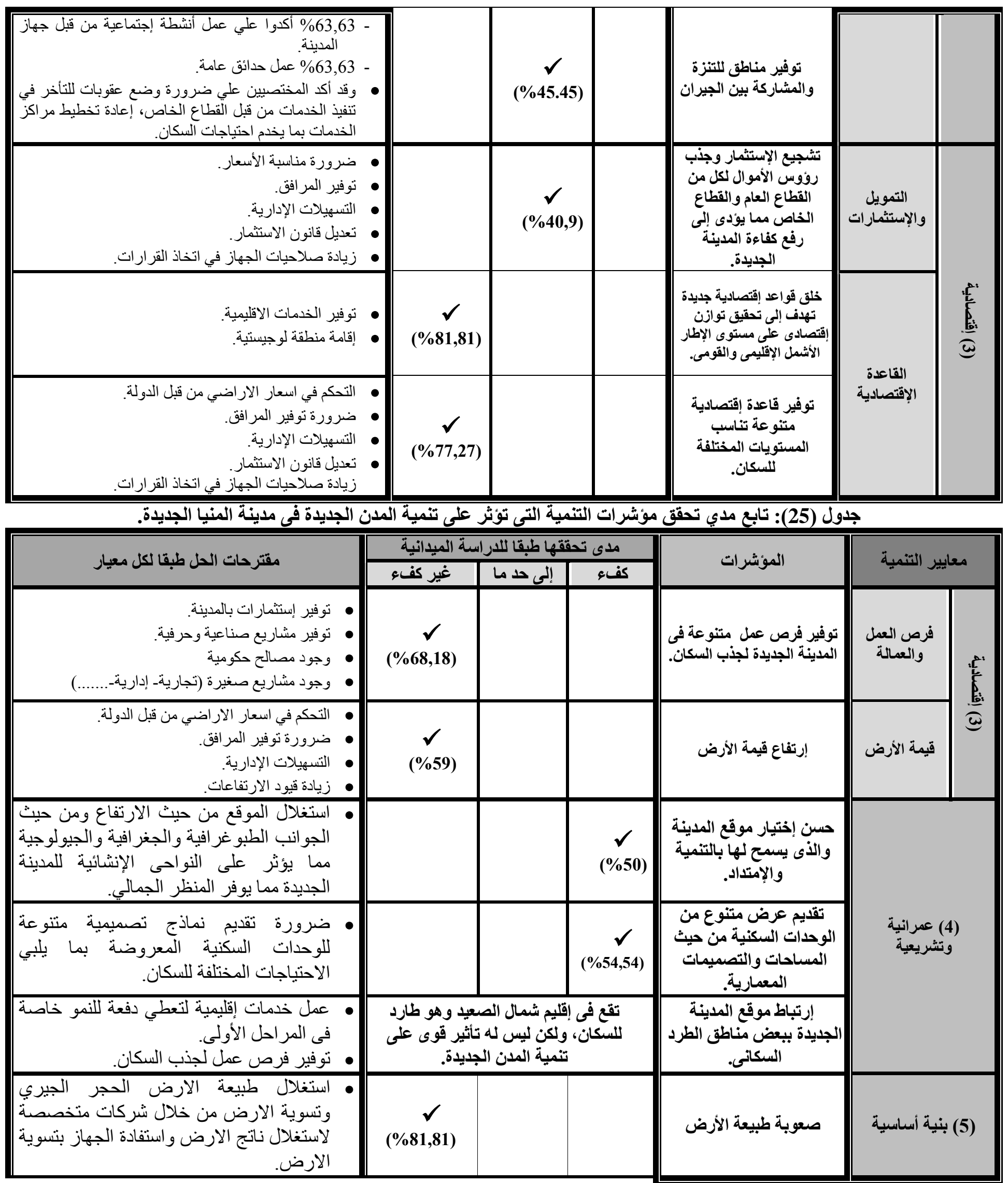


Vol. 41, No.2. July 2022

\begin{tabular}{|c|c|c|c|c|c|}
\hline 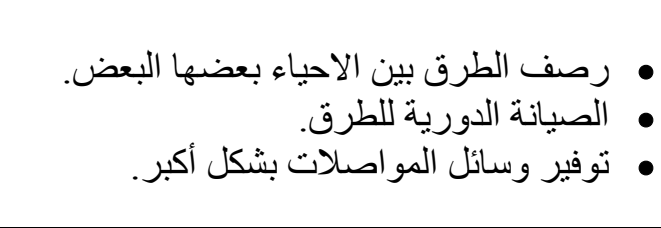 & & $\begin{array}{r}\checkmark \\
(\% 50)\end{array}$ & & 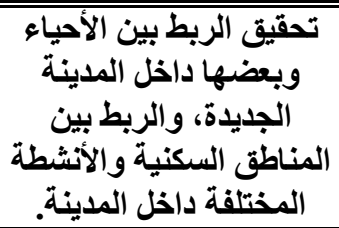 & \\
\hline 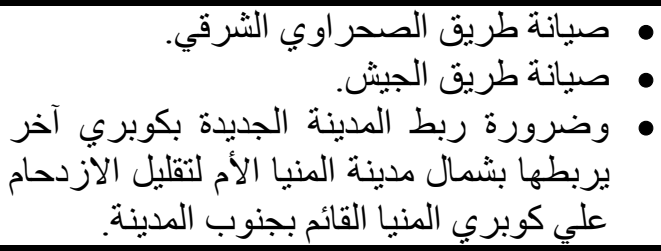 & & & $\begin{array}{c}\checkmark \\
\% 45,45) \\
(\end{array}$ & 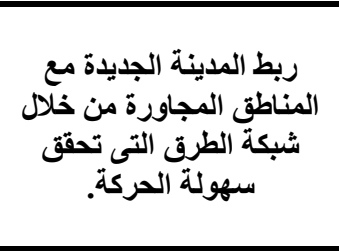 & \\
\hline 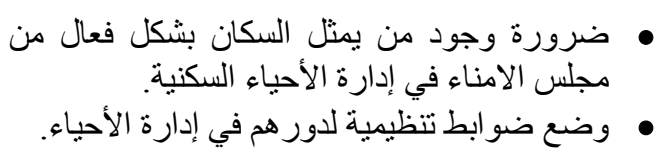 & $\begin{array}{c}\checkmark \\
(\% 63,63)\end{array}$ & & & مشاركة السكان الفعلية فى إتخاذ الجرارة بالمدينة & وسياسية \\
\hline 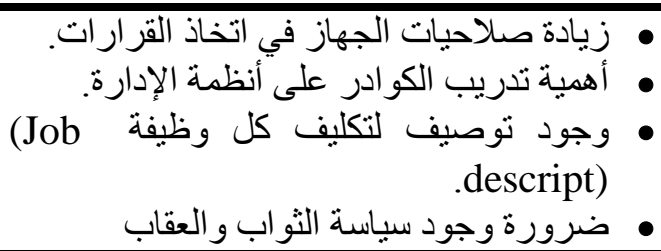 & $\begin{array}{c}\checkmark \\
(\% 59,09)\end{array}$ & & & مشكلة في تراخيص المباني & \multirow{2}{*}{ وسياسية إدية } \\
\hline 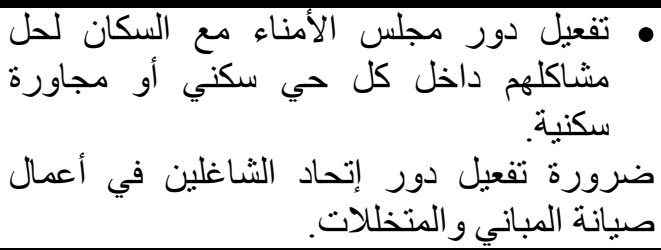 & $\begin{array}{c}\checkmark \\
(\% 86,36)\end{array}$ & & & السكان في إدارية تو اجه & \\
\hline
\end{tabular}

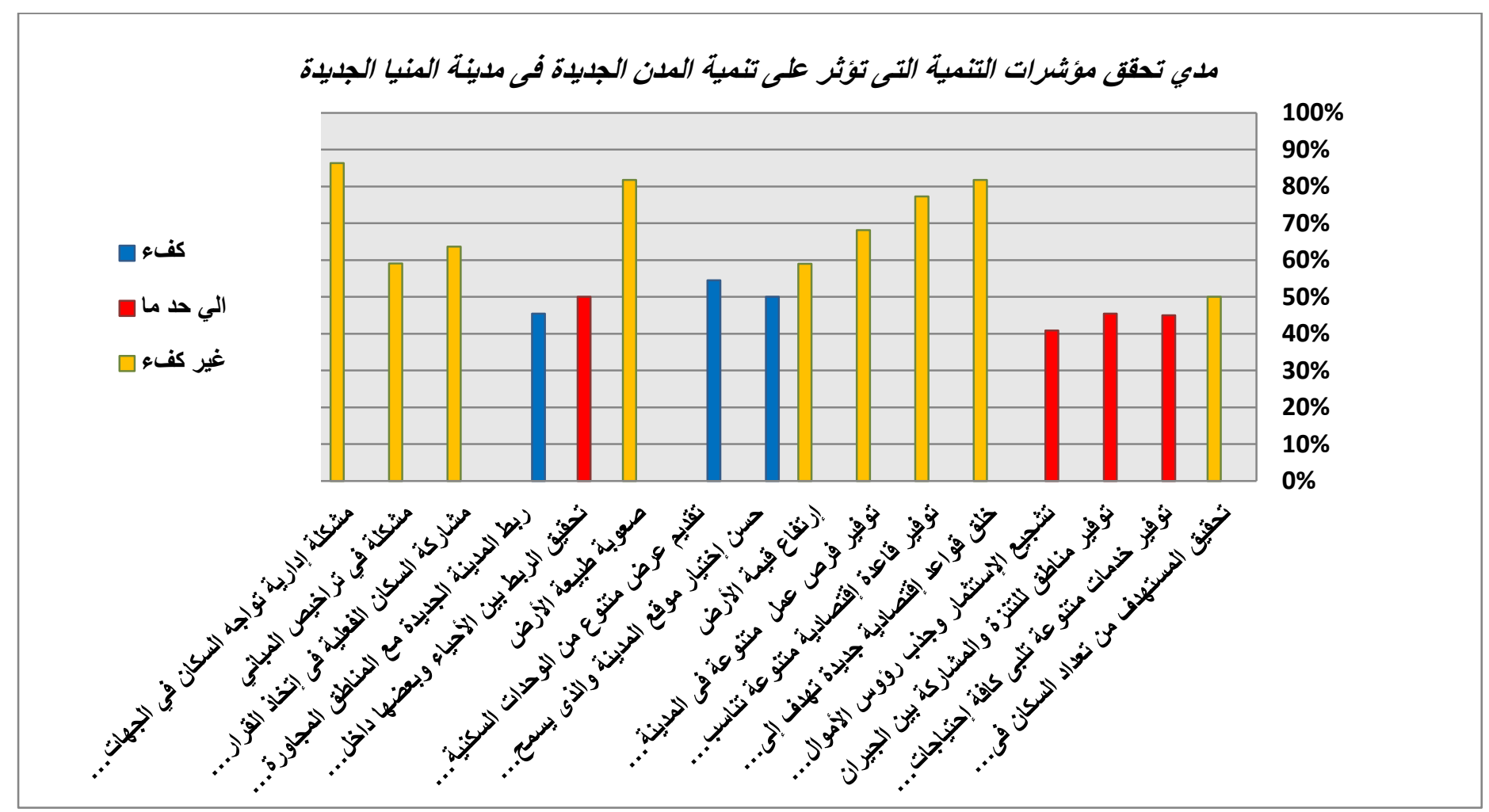

و عليه يقترح البحث تقديم هذا الجدول كدليل استرشادي لجهاز مدينة المنيا الجديدة للتعرف علي مؤشرات التنمية التي بها قصور بمنطقة الدر اسة ومن ثم إمكانية تداركها لرفع كفاءتها من خلال المقترحات الموضو عة بما يحقق التنمية المنشودة. 
Vol. 41, No.2. July 2022

5. ضرورة زيادة عو امل جذب السكان مثل توفير المشروعات المنات

الصناعية و الجامعات و المناطق الترفي فئية.

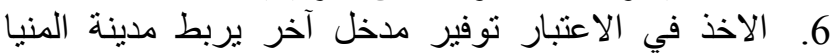

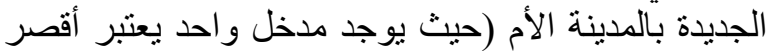

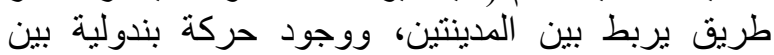
المدينة الجديدة و المدينة الأم بإعتبار معظم السكان بلئ يعملون

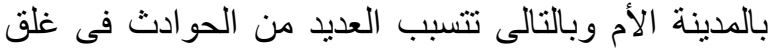
الطريق لفترة مما يعطل الحركة).

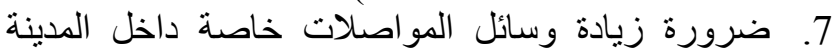
وتكون منتظمة للربط بين الأحياء المختلفة وبأسعار مناسبة.

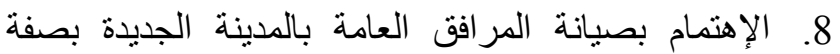

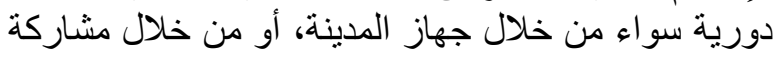

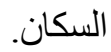

9. ضرورة دعم مشاركة القطاع الخاص فى الإستثمار بمدينة

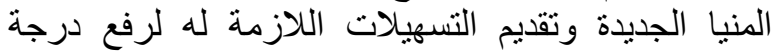

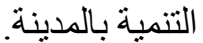
10. الاهتمام بالتنسيق بين الهيئات الإدارية المختلفة للمشاركة في تنمية المدينة.

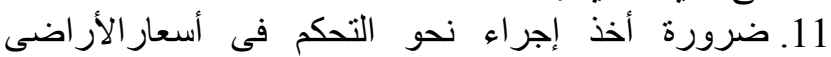

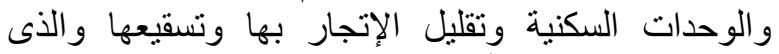
يتسبب في عدم تحقق أهداف إنشاء المدينة الجديدة.

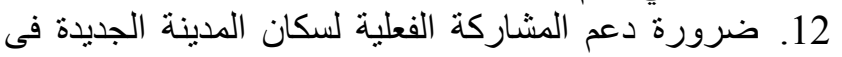

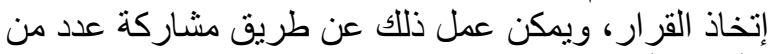

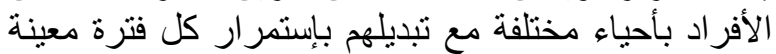
لتقليل ظهور المصالح الثخصية على بلى حساب مصلحة المدينة وتتميتها.

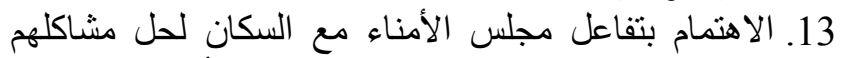

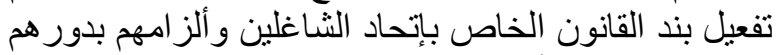

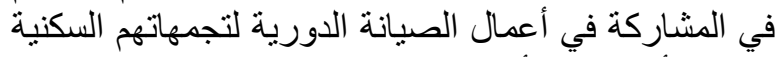

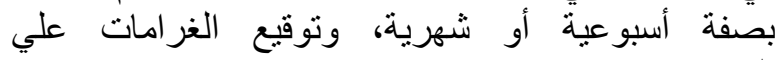
المتقاعسين. 14. ضرورة زيادة صلاحيات الجهاز في اتخاذ القرارات. 15. 15 الاهتمام تدريب الكوادر على على أنظمة الإدارة.

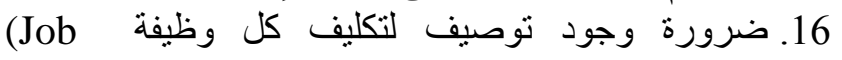
.descript) 18. ضرورة وجود سياسة الثواب و العقاب. 18. الاخذ في الاعتبار استخلال طبيعة الارض ابرض الحجر الجيري

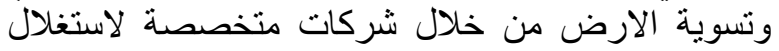

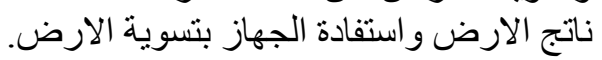

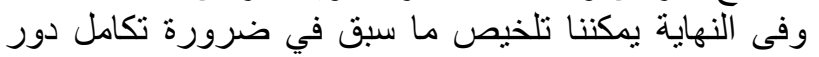

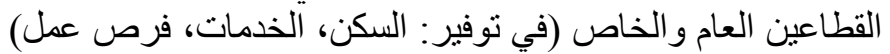

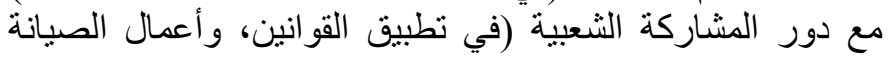

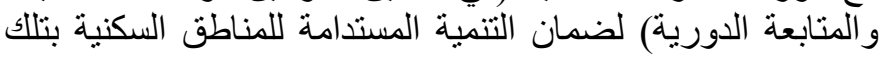

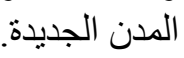

من الدراسة النظرية والميدانية نوصل البحث إلي عدة نتائج و أهمها:

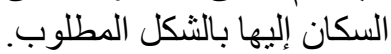

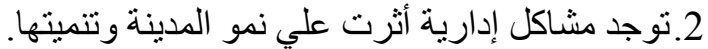
3. عدم مشاركة السكان بشكل فعال في تنمية الثدينة الثينة.

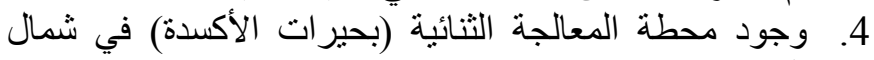

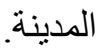

5. عدم وجود المسطحات الخضراء، والأنشطة الإجنماعية و الحدائق العامة.

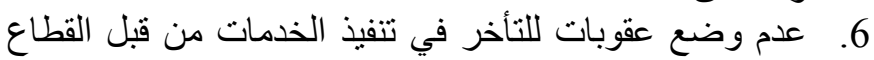
الخاص، وتخطيط مر اكز الخدمات لا يخدم احتياجات السكان

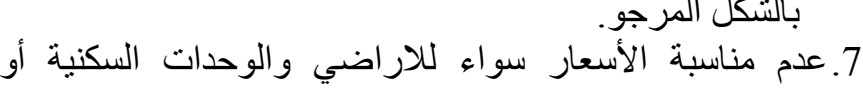

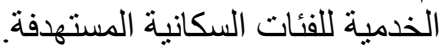

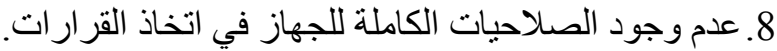

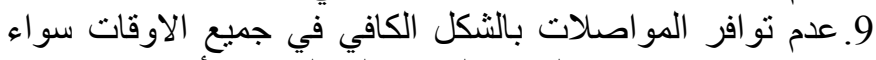
بين الاحياء او من المدينة الجديدة إلي المدينة الأم. 10. عدم تو افر الخدمات الاقليمية واللوجيسية الإنية بالمدينة. 11. 11 عدم تدريب الكو ادر على أنظمة الإدارة.

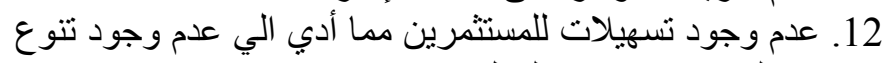

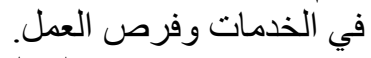
13. عدم وجود مصانع بالشكل الكبير الذي يوفل الذبر فرص للعمل ويحقق الاكتفاء الذاتي المرجو.

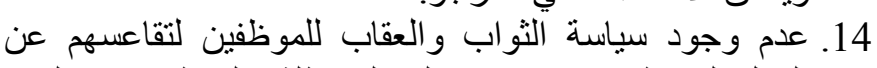
العمل المنوط بهم مما يؤدي إلي المماطلة و التباطؤ في عمليات

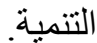

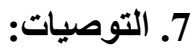

الدن خلال الدراسة النظرية والدراسة الميدانية لمدينة المنيا

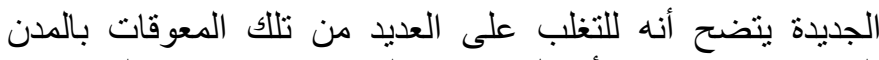

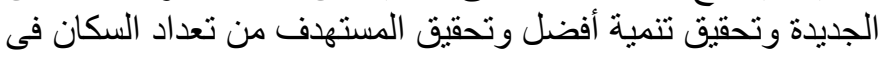
مخطط المدينة فإن البحث يوصية لفي بالآتي:

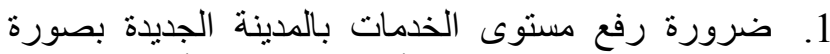
تميزها عن مدينة المنيا الأم و التحكم فى بلى أسعارها حتى الخى تساعد في جذب السكان. 2. ضرورة مراعاة التوزيع المتوازن للخدمات على كافة الأحياء.

3. الاخذ في الاعتبار التوسع فى إقامة الصناعات المعتمدة

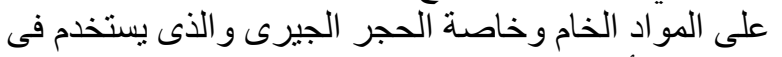
صناعة الأسمنت وحجر البناء وخاهة الزجاج الجيرى والسير اميك، مع في في

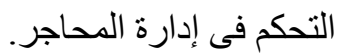
4. الالهمام بزيادة فرص العمل العل عن طريق نوفير قاعدة إقتصادية متنوعة للسكان، ومحاولة حل مشاكل المصنانع

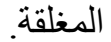


المراجع :- تقرير التنمية البشرية في مصر ، اللامركزية من أجل الحكم الرشيد، القاهرة، 2004

2- Abdel Waha, S and Mamdouh, I., (2001), "Policies for the Enhancement of Local Government Resources", Public Administration Research and Consultation Center, Cairo University, Paper \# 6

3- ESCWA, (2001), "Decentralization And The Emerging Role of Municipalities In The Escwa Region", United Nations, New York

4- باهر إسماعيل حلمي فرحات ، تأثير لامركزية الإدارة علي التنمية العمر انية في مصر ، رسالة دكتورة ، كلية الهندسة ، جامعة عين شمس ، 2006

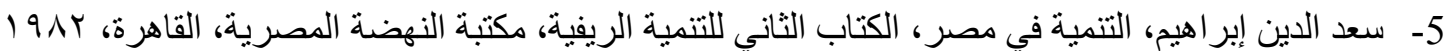

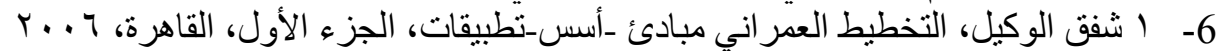

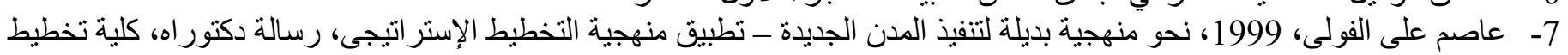
إقليمى و عمر انى، جامعة القولى،

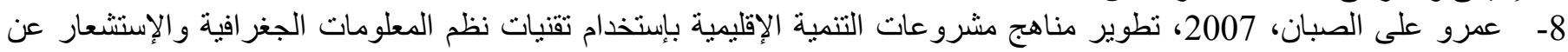

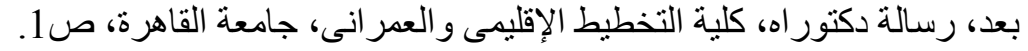

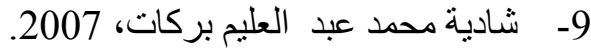
10 - حازم عبد العظيم حماد، 1994

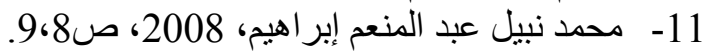

12- باهر إسماعيل حلمى فرحات، 2006، عيد، نأثير لامركزية الإدارة على التنمية العمرانية فى مصر، رسالة دكتور اة، كلية الهندسة، جامعة

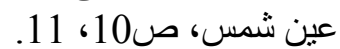

13- رانيا أدهم سيد محمد على، 12، 2012، المدن الجديدة فى مصر بين المستهدف و الو اقع-حالة مدينة السادس من أكتوبر ، رسالة ماجيستير،

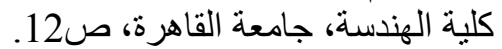

14- 1 El Sawy, Aly, "Governors without Governance Constitutional, Legal and Administrative Frameworks of Legal Governments in Egypt, Mediterranean Development Forum UNDP, undated, Good Local Governance Self Assessment Tool, 2000.

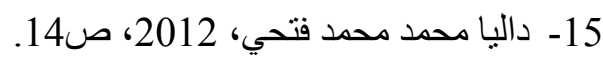

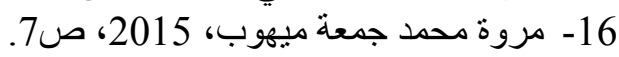

$$
\begin{aligned}
& \text { 17- مادة رقم (1) قانون إنشاء المجتمعات العمر انية الجديدة رقم } 59 \text { لسنة } 1979 .
\end{aligned}
$$

18- 2ESCWA, Decentralization And The Emerging Role of Municipalities In The Escwa Region, United Nations, New York, 2001

19- 1 ESCWA- Decentralization And The Emerging Role of Municipalities In The Escwa Region, United Nations, New York, 2001

$$
\begin{aligned}
& \text { 20- تقرير التنمية البشرية في مصر، اللامركزية من أجل الحكم الرشيد، القاهرة، ع . . ب }
\end{aligned}
$$

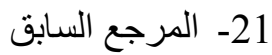

$$
\begin{aligned}
& \text { 22- الموقع الرسمى لهيئة المجتمعات العمر انية الجديدة (www.newcities.com) }
\end{aligned}
$$

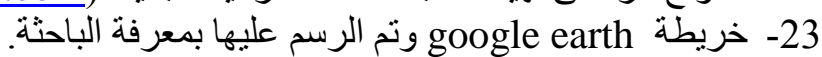

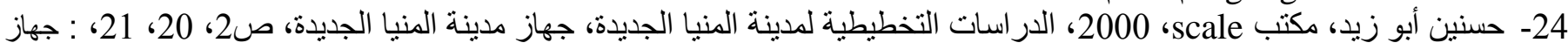

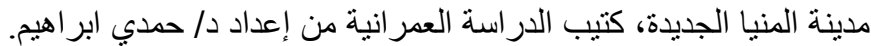

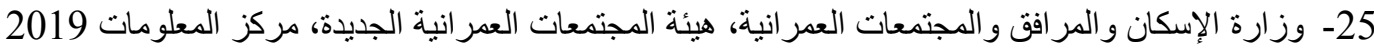

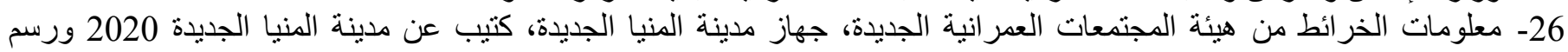
الخريطة من إعداد الباحثة.

27- معلومات الخر ائط من هيئة المجتمعات العمرانية الجديدة، جهاز مدينة المنيا الجديدة، كتيب عن مدينة المنيا الجديدة 2020 ورسم الخريطة من إعداد الباحثة.

28- المصدر: وزارة الإسكان و المر افق والمجتمعات العمر انية، هيئة المجتمعات العمرانية الجديدة، مركز المعلومات، ملخص عن انجازات المدينة. 
Vol. 41, No.2. July 2022

(ملحق أ)

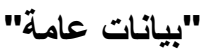

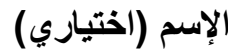

أولاً: "معايير بيئية"

1. هل هناك مشاكل بيئيه تعانون منها؟ ماهي؟

\begin{tabular}{|c|c|c|}
\hline \hline & يوجد|| \\
\hline & & \\
\hline
\end{tabular}

口 مشكلة مناخية من حيث درجة الحرارة.

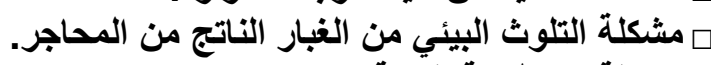
口 مشكلة مع طبيعة التربة. 口 مشكلة تلوث بيئي ناتج عن الصرف الصحي. هآخري. 2. ماهي مقترحاتك للتظلب عليها؟

مزرأعة حزام شجري حول المدينة.

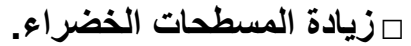

هزيادة المسطحات المتخللة بين المناطق المطاء السكنية.

ثانياً: المعايير السكانية والإجتماعية"

ه عمل محطات معالجة ثلاثية.

هل توجد مشكله في توافر الخدمات بالمدينه؟ ما هي؟

\begin{tabular}{|c|c|c|c|c|c|c|}
\hline \multicolumn{3}{|c|}{ مدي الرضي عن قـربهـا من المنزل } & \multirow{2}{*}{ توجد إلي حـاً } & \multirow{2}{*}{ لا توجد } & \multirow{2}{*}{ 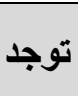 } & \multirow{2}{*}{ 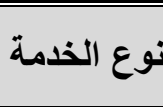 } \\
\hline إلي حداً ما & غير مرضي & مرضي & & & & \\
\hline & & & & & & إداري \\
\hline & & & & & & تجاري \\
\hline & & & & & & ديني \\
\hline & & & & & & تعليمي \\
\hline & & & & & & الأمن \\
\hline & & & & & & آخري \\
\hline
\end{tabular}

4. هل يتو افر مناطق للتنزه والمشاركه بين الجيران بعضهم البعض بالثكل الكافي؟

\begin{tabular}{||c|c|c|}
\hline & يوجا \\
\hline & & \\
\hline
\end{tabular}

5. ما هي المقترحات للتظلب علي تلك المشكلات؟

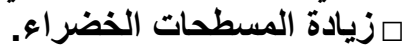

ه عمل أنشطة إجتماعية من قبل جهاء المبل المدينة.

ثنالثاً: "المعايير الإقتصاديةة" 口 عمل حدائق عامة.

6. ما مدي رضاك عن حجم ونوع الاستثمارات بالمدينه؟

\begin{tabular}{||c|c|c|}
\hline \hline & & \\
\hline & & \\
\hline
\end{tabular}

7. هل توجد عناصر للجذب الاستثمار بالمدينه؟ لماذا؟

بوجد إلى حـاً مـا

ل ايوجد

يوجا 
Vol. 41, No.2. July 2022

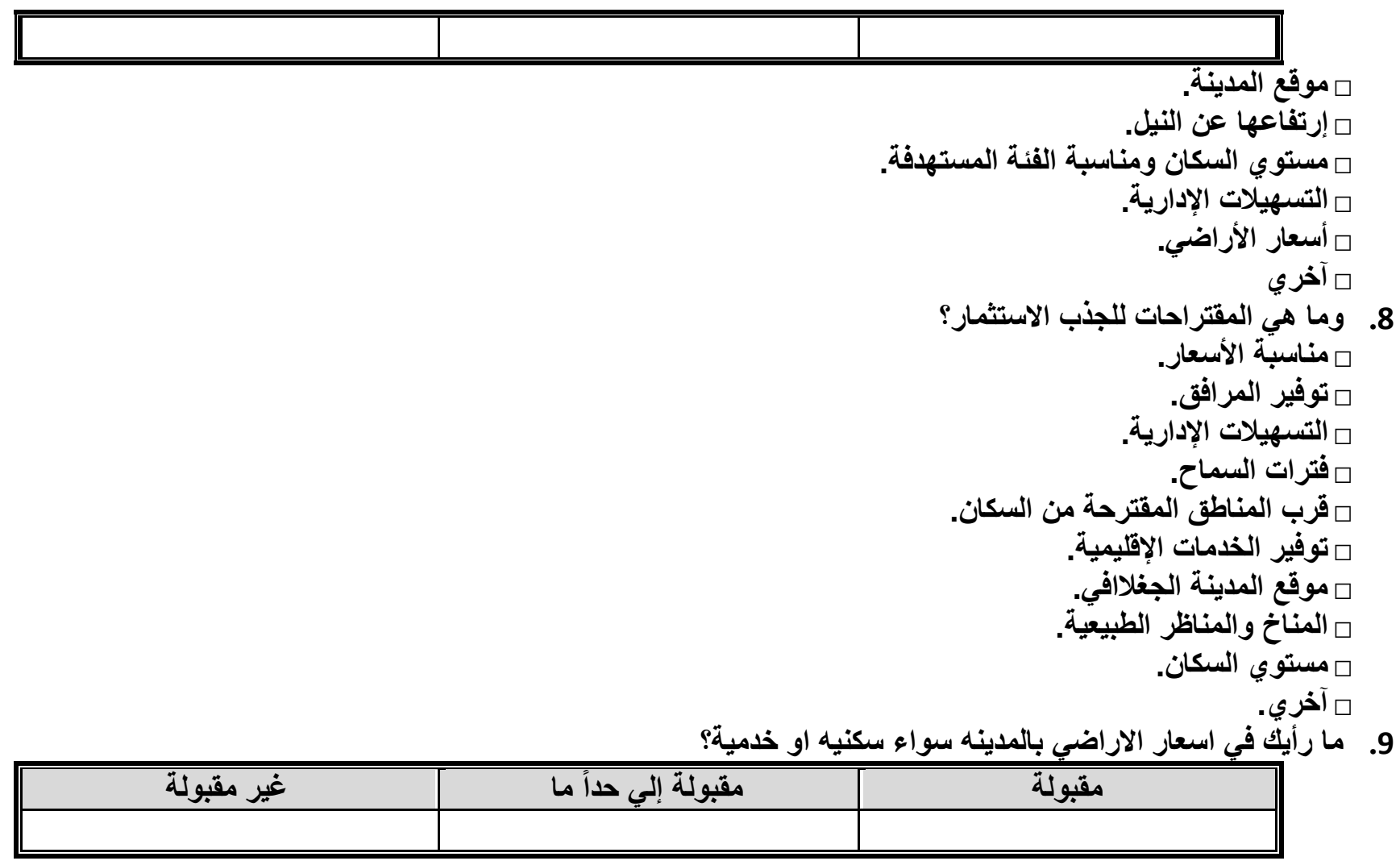

10. ما رأيك في اسعار الاراضي بمنطقة الامتداد بالمدينة سواء سكنية أو خدمية؟

\begin{tabular}{|c|c|c|}
\hline غير مقبولة & مقبولة إلى حداً مـا & مقبولة \\
\hline
\end{tabular}

11. هل توجد فرص عمل بثكل كافي بمدينة المنيا الجديدة؟ لماذا لا توجد حال عدم وجودها؟

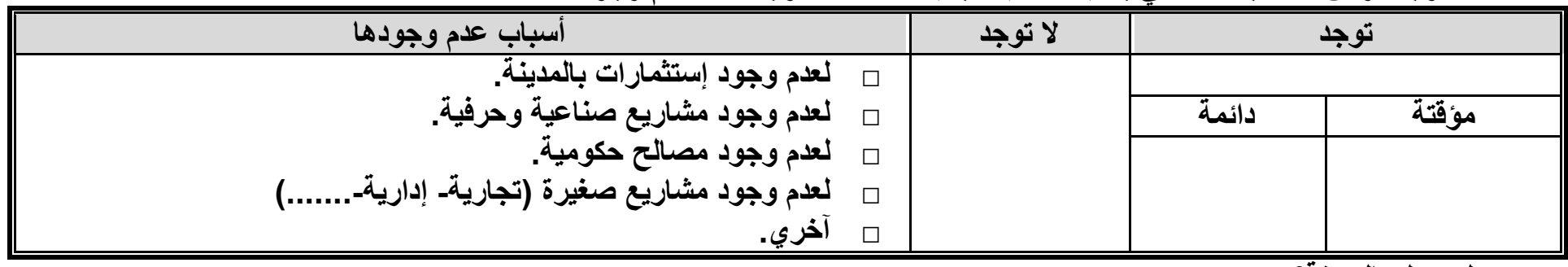

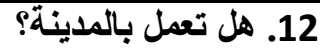

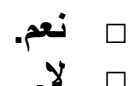

رابعاً: "المعاييز العمر انية"

13. ما المسافة بين المنزل و العمل؟

\begin{tabular}{||c|c|c|}
\hline \hline قريبة & \\
\hline & & \\
\hline
\end{tabular}

14. هل يوجل مكان للإقامة تملكه (قطعة أرض / وحدة سكنية)؟ في حالة الإيجار، مدي رضاك عن السعر؟

\begin{tabular}{||l|l|l||}
\hline \hline & مرضي & \\
\hline & & \\
\hline
\end{tabular}

15. هل ترغب في بيع (قطعة الأرض / الوحدة السكنية)؟




Vol. 41, No.2. July 2022

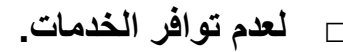

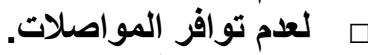

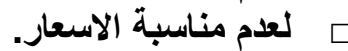

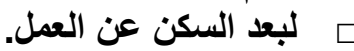

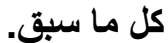

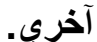

16. هل مكان الإقامة مناسب لعدد أفراد الأسرة؟ وما عددهر؟

\begin{tabular}{||c|c|c|}
\hline \hline هناسبة & \\
\hline & & \\
\hline
\end{tabular}

عددهم

17. منذ متي تقطن بالمدينة؟ عدم

18. ما مدي ملائمة موقع المدينة والرضا عليه؟

\begin{tabular}{||c|c|c||}
\hline & ملانم ومرضي & \\
\hline & & \\
\hline & & \\
\hline
\end{tabular}

خامسأ: "معايير البنية الأساسية"

19. هل تجد صعوبة في طبيعة الأرض؟ ما هي؟

\begin{tabular}{||c|c|c|}
\hline \hline & توجد|| & \\
\hline & & توجد \\
\hline
\end{tabular}

ه " طبيعية التربة الصخرية تزيد من تكلقة الحفر.

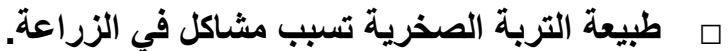

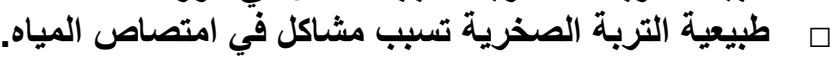

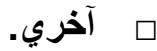

20. هل توجد مشكلة في الإتصال بين المدينة الجديدة والمدينة الأم؟ ما هي؟ توجي

\begin{tabular}{|c|c|c|}
\hline توجد إلي حداً مـا & لا توجد & توجد \\
\hline & & \\
\hline
\end{tabular}

مدم توافر وسائل النقل بالثكل الكافي.

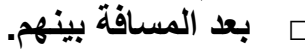

口 الإزدحام علي الكوبري الرابط بينهم.

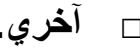

21. هل توجد مشكلة في المرافت (مياه، صرف، ري، كهرباء، اتصالات، زراعة، غاز ...)؟ ما هي؟

\begin{tabular}{|c|c|c|c|c|c|c|c|c|}
\hline آخري & غاز & زراعة & اتصالات & كهرباء & ري & صرف & مياه & نوع المرفق \\
\hline & & & & & & & & توجد \\
\hline & & & & & & & & لا توجد \\
\hline & & & & & & & & توجد إلي حداً ما \\
\hline
\end{tabular}

22. هل تتو افز المواصلات بالثكل الكافي؟ بجميع الاوقات والأماكن؟

\begin{tabular}{||c|c|c|}
\hline \hline & توجد|| \\
\hline & & \\
\hline
\end{tabular}

23. هل توجل رقابة علي أسعار المواصلات؟

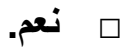

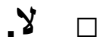

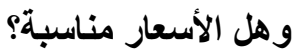

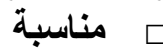


Vol. 41, No.2. July 2022

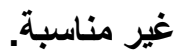

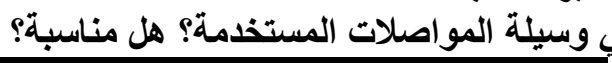

. 24

\begin{tabular}{||c|c|c|}
\hline \hline & مناسبةً & \\
\hline & & \\
\hline
\end{tabular}

سادساً: "معاييز إدارية وسياسية"

25. هل يوجد مشكلة في تراخيص المباني؟ ما هي؟

\begin{tabular}{||l|l|l||}
\hline \hline توجد|| & توجد \\
\hline & & \\
\hline
\end{tabular}

م إم سهولة الإجراءات من قبل جهاز المدينة.

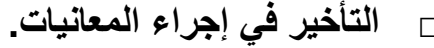

口 جمود قانون البناء 119.

آخري.

26. هل يوجد مشيكلة إدارية تواجه السكان في الجهات الإدارية بالمدينة فيما يخص تنميتها؟ ما هي؟

أسباب وجودها: أنها

口 عدم تفاعل مجلس الأمناء مع السكان لحل مشاكلهم.

口 عدم تفعيل إتحاد الشاغلين.

口 آخري.

27. هل توجل مشكلة بالنماذج المفروضة من قبل جهاز المدينة؟ ما هي؟

\begin{tabular}{||l|l|l||}
\hline \hline مناسبة & \\
\hline & & \\
\hline
\end{tabular}

28. ما رأيك بأسلوب إدارة المدينة من حيث مشاركة السكان في تنميتها؟

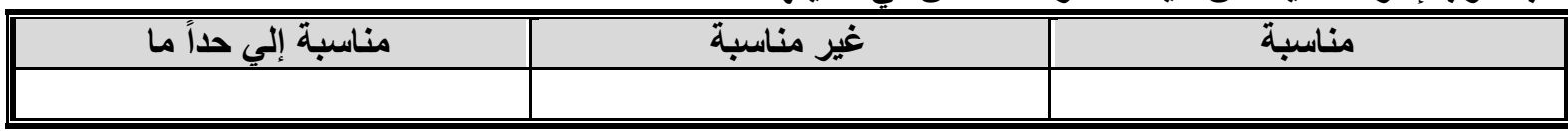

29. هل يوجد من يمثلكم من السكان؟

هل علي تواصل مستمر معد.

$\square$
نعم. $\quad \square$

30. هل تفضل إتخاذ القرار بالتواصل مع السكان؟

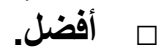

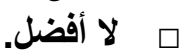

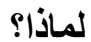

口 بإعتبار السكان هم الأين يشعرون بما يحتاجونه أكثر من متذذي القرار.

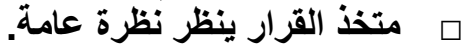

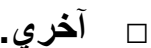

31. هل ترغب في الإستمر ار في العيش بالمدينة؟

أرغب إلي حداً ما

لأرغب أرغب ارغي

$$
\text { (ملحق ب) }
$$

"بيانات عامة" 
Vol. 41, No.2. July 2022

الإسم (اختياري)

أولاً: "معايير بيئية"

1. هل هناك مشاكل بيئيه تعانون منها؟ ماهي؟

\begin{tabular}{||c|c|c||}
\hline \hline يوجد|| & \\
\hline & & \\
\hline
\end{tabular}

ه مشكلة مناخية من حيث درجة الحرارة.

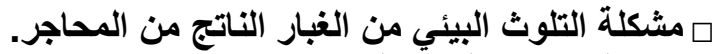

口 مشكلة مع طبيعة التربية. 口 مشكلة تلوث بيئي ناتج عن الصرية مثرف الصحي.

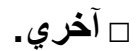

2. ماهي مقترحاتك للتظلب عليها؟

هزرأعة حزام شجري حول المدينة.

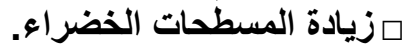

هزيادة المسطحات المتخللة بين المناطق المطكنية.

ثانياً: المعاييز السكانية والإجتماعية"

ه عمل محطات معالجة ثلاثية.

هل توجد مشكله في توافر الخدمات بالمدينه؟ ما هي؟

\begin{tabular}{|c|c|c|c|c|c|c|}
\hline \multicolumn{3}{|c|}{ مدي الرضي عن قـربهـا من المنزل } & \multirow{2}{*}{ توجد إلي حداً } & \multirow{2}{*}{ لا توجد } & \multirow{2}{*}{ توجل } & \multirow{2}{*}{ نوع الخدمة } \\
\hline إلي حداً ما & غير مرضي & مرضي & & & & \\
\hline & & & & & & إداري \\
\hline & & & & & & تجاري \\
\hline & & & & & & ديني \\
\hline & & & & & & ت تعليمي \\
\hline & & & & & & الأمن \\
\hline & & & & & & آخري \\
\hline
\end{tabular}

4. هل يتو افر مناطق للتنزه و المشاركه بين الجيران بعضهم البعض بالثكل الكافي؟

\begin{tabular}{||c|c|c|}
\hline \hline & يوجد|| \\
\hline & & \\
\hline
\end{tabular}

5. ما هي المقترحات للتظلب علي تلكك المشكلات؟

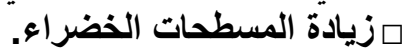

ه عمل أنشطة إجتماعية من قبل جهاز المبل المدينة.

ثالثثاً: "المعايير الإقتصادية"

ه عمل حدائق عامة.

6. ما مدي رضاك عن حجم ونوع الاستثمارات بالمدينه؟

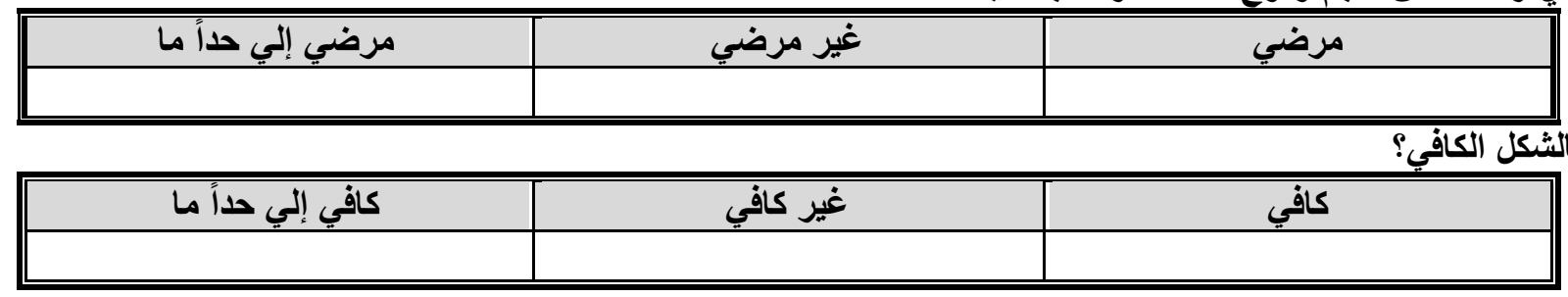

7. هل توجد عناصر للجذب الاستثمار بالمدينه؟ لماذا؟

\begin{tabular}{|c|c|c|}
\hline يوجد إلي حداً ما & لا يوجد & يوجد ي \\
\hline
\end{tabular}


Vol. 41, No.2. July 2022

口 مستوي السكان ومناسبة الفئة المستهذفة. 口 التسهيلات الإدارية.

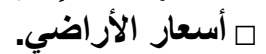
هـ آخري 8. وما هي المقتراحات للجذب الاستثمار؟

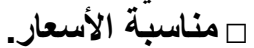

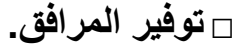
口 التسهيلات الإدارية. ه فترات السماح. هقرب المناطق المقترحة من السكان. 口 توفير الخدمات الإقليمية. 口 موقع المدينة الجغلافئ. 口 المناخ والمناظر الطبيعية.

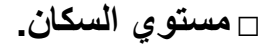

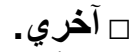

9. ما رأيك في اسعار الاراضي بالمدينه سواء سكنيه او خدمية؟

\begin{tabular}{|c|c|c|}
\hline غير مقبولة & مقبولة إلى حـاً مـا & مقبولة \\
\hline
\end{tabular}

10. ما رأيك في اسعار الاراضي بمنطقة الامتداد بالمدينة سواء سكنية أو خدمية؟

\begin{tabular}{||c|c|c|}
\hline \hline & مقبولة & \\
\hline & & \\
\hline
\end{tabular}

11. هل توجد فرص عمل بثكل كافي بمدينة المنيا الجديدة؟ لماذا لا توجد حال عدم وجودها؟

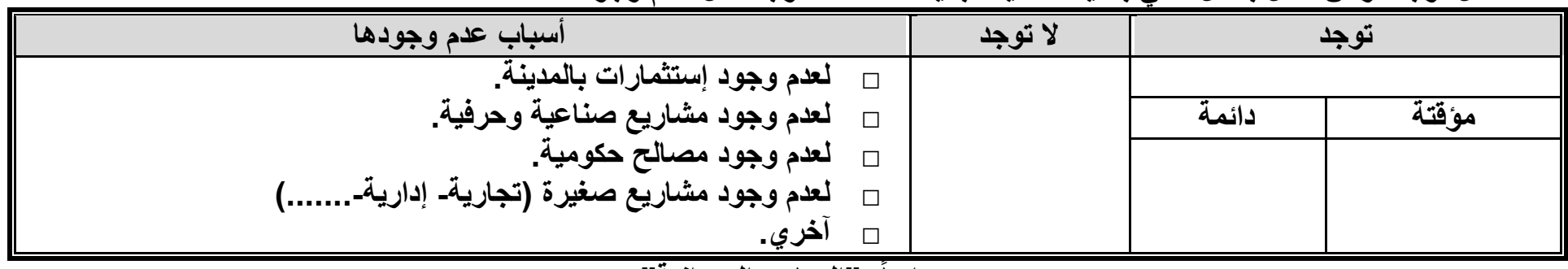

$$
\text { رابعاً: "المعايير العمر انية" }
$$

12. ما مدي ملائمة موقع المدينة والرضا عليه؟

\begin{tabular}{|c|c|c|}
\hline ملائم ومرضي إلي حداً ما & غير ملائم وغيرمرضي & ملائم ومرضي \\
\hline & & \\
\hline
\end{tabular}

$$
\text { خامساً: "معاييز البنية الأساسية" }
$$

13. هل تجد صعوبة في طبيعة الأرض؟ ما هي؟

\begin{tabular}{||c|c|c|}
\hline \hline & توجد|| & \\
\hline & & \\
\hline
\end{tabular}

口 طبيعية التربة الصخرية تزيل من تكلفة الحفر.

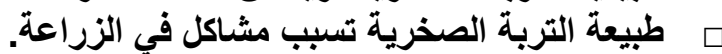

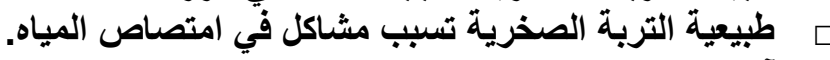

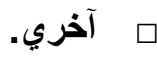

\begin{tabular}{|c|c|c|}
\hline توجد إلي حداً ما & لا توجد & توجل \\
\hline
\end{tabular}

14. هل توجد مشكلة في الإتصال بين المدينة الجديدة والمدينة الأم؟ ما هي؟

عدم توافر وسائل النقل بالثكل الكوافي. 
Vol. 41, No.2. July 2022

口 بعد المسافة بينهم.

口 الإزدحام علي الكوبري الرابط بينهم.

口 آخري.

15. هل توجد مشكلة في المرافق (مياه، صرف، ري، كهرباء، اتصالات، زراعة، غاز ...)؟ ما هي؟

\begin{tabular}{|c|c|c|c|c|c|c|c|c|}
\hline آخري & غاز & زراعة & اتصالات & كهرباء & ري & صرف & مياه & نوع المرفق \\
\hline & & & & & & & & توجد \\
\hline & & & & & & & & لا توجد \\
\hline & & & & & & & & توجد إلي حداً ما \\
\hline
\end{tabular}

16. هل تتوافر المواصلات بالثكل الكافي؟ بجميع الاوقات والأماكن؟

\begin{tabular}{||c|c|c||}
\hline \hline & توجد|| \\
\hline & & \\
\hline
\end{tabular}

17. هل توجل رقابة علي أسعار المواصلات؟

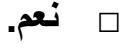

口 الأ

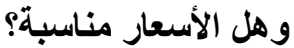

口 مناسبة منية

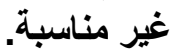

18. ما هي وسيلة المواصلات المستخدمة؟ هل مناسبة؟

\begin{tabular}{||l|c|c|}
\hline \hline & مناسبةً & \\
\hline & & \\
\hline
\end{tabular}

سادساً: "معايير إدارية وسياسيةة"

19. هل يوجد مشكلة في تراخيص المباني؟ ما هي؟

توجد إلي حداً ما

لا توجد توجد

عدم سهولة الإجراءات من قبل جهاز المدينة.

التأخير في إجراء الإجراء المعانيات.

جمود قانون البناء الجراء العمانيات.

آخري.

$\square$

$\square$

20. هل يوجد مشكلة إدارية تواجه السكان في الجهات الإدارية بالمدينة فيما يخص تنميتها؟ ما هي؟

أسباب وجودهيا

لا توجل

توجد

口 عدم تفاعل مجلس الأمناء مع السكان لحل مشاكلهم.

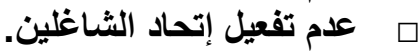

口 آخري. 